\title{
Nucleocytoplasmic transport blockage by SV40 peptide-modified gold nanoparticles induces cellular autophagy
}

This article was published in the following Dove Press journal:

International Journal of Nanomedicine

5 October 2012

Number of times this article has been viewed

\section{Tsung-Lin Tsai ${ }^{1,5}$ \\ Chia-Cheng Hou ${ }^{1,5}$ \\ Hao-Chen Wang 1,5 \\ Zih-Syuan Yang ${ }^{2}$ \\ Chen-Sheng Yeh ${ }^{4}$ \\ Dar-Bin Shieh",3 \\ Wu-Chou Su ${ }^{1,5}$}

'Institute of Basic Medical Sciences, ${ }^{2}$ Institute of Oral Medicine and Department of Stomatology, ${ }^{3}$ Center for Micro/Nano Science and Technology, ${ }^{4}$ Department of Chemistry, National Cheng Kung University, Tainan, Taiwan; ${ }^{5}$ Department of Internal Medicine, National Cheng Kung University Hospital, College of Medicine, National Cheng Kung University, Tainan, Taiwan
Correspondence:Wu-Chou Su Department of Internal Medicine, National Cheng Kung University Hospital, College of Medicine, National Cheng Kung University, No. I38, Sheng Li Road,Tainan 704, Taiwan $\mathrm{Tel}+88662353535 \# 3120$

Fax +886 62084112

Email sunnysu@mail.ncku.edu.tw

Dar-Bin Shieh

Institute of Oral Medicine and Department of Stomatology, National Cheng Kung University Hospital, College of Medicine, National Cheng Kung University, No. I38, Sheng Li Road,

Tainan 704, Taiwan

Tel +886 $62353535 \# 5410$

Fax +88662766626

Email dshieh@mail.ncku.edu.tw
Abstract: Gold nanoparticles modified with the nuclear localization signal from simian virus 40 large T antigen (GNP-PEG/SV40) accumulate on the cytoplasmic side of the nuclear membrane in HeLa cells. Accumulation of GNP-PEG/SV40 around the nucleus blocks nucleocytoplasmic transport and prevents RNA export and nuclear shuttling of signaling proteins. This long-term blockage of nucleocytoplasmic transport results in cell death. This cell death is not caused by apoptosis or necrosis because caspases 3 and 9 are not activated, and the expression of annexin V/propidium iodide is not enhanced in HeLa cells after treatment. Using transmission electron microscopy, autophagosomes and autolysosomes were seen to appear after 72 hours of treatment with GNP-PEG/SV40. Increasing levels of enhanced green fluorescent protein-microtubule-associated protein 1 light chain 3 (EGFP-LC3)-positive punctate and LC3-II confirmed GNP-PEG/SV40-induced autophagy. In SiHa cells, treatment did not induce accumulation of GNP-PEG/SV40 around the nucleus and autophagy. Treating cells with wheat germ agglutinin, a nuclear pore complex inhibitor, induced autophagy in both HeLa and SiHa cells. GNP-PEG/SV40-induced autophagy plays a role in cell death, not survival, and virus-mediated small hairpin RNA silencing of Beclin-1 attenuates cell death. Taken together, the results indicate that long-term blockade of nucleocytoplasmic transport results in autophagic cell death.

Keywords: gold nanoparticles, nucleocytoplasmic transport blockage, autophagy, wheat germ agglutinin

\section{Introduction}

Nanoparticles are ideal vectors for delivering analytic probes or therapeutic agents to cells and subcellular compartments. Gold nanoparticles are widely used as a model platform for biomedical research because of their favorable physical and chemical properties. Cellular uptake of gold nanoparticles is highly dependent on their size, shape, and surface properties. ${ }^{1-4}$ In general, internalization of nanoparticles within the cell nucleus is achieved by cellular uptake of nanoparticles through endocytosis. ${ }^{5}$ The nanoparticles escape from transport vesicles and target different organelles, such as the nuclear membrane, then cross the nuclear pore complex barrier and translocate into the nucleus. ${ }^{6}$ Tkachenko et al $^{7}$ reported that gold nanoparticles modified with an SV40 peptide were able to penetrate the cellular membrane and escape the endosomal pathway within one hour, and then accumulate around the nuclear membrane after 2 hours of treatment. This phenomenon did not occur when the modified peptide was changed from SV40 to adenovirus (ADV) or in other cell types, such as 3T3/NIH and HepG2. The outcome in this regard is highly dependent on the peptide sequence and cell type. ${ }^{8}$ 
Although the cellular trajectories of nanoparticles have been demonstrated, the long-term effects of intracellular nanoparticles on cells are not fully understood. Many studies have reported on short-term particle exposure (2-12 hours), which is not sufficient for detecting the overall cellular response and subsequent functional changes. Mironava et $\mathrm{al}^{9}$ found that gold nanoparticles, regardless of surface coating, are toxic to human dermal fibroblasts upon long-term exposure of the cells to $13 \mathrm{~nm}$ and $45 \mathrm{~nm}$ particles (at 72 and 144 hours, respectively). In the present study, the long-term toxic effects of peptide-modified gold nanoparticles that localize in specific cell areas were examined to identify the underlying mechanisms of toxicity.

The nuclear pore complex is the primary conduit for communication between the cell nucleus and cytoplasm, with a mean functional diameter of approximately $39 \mathrm{~nm} .{ }^{10-13}$ The transport of transcriptional regulators into the nucleus and RNA out of the nucleus is essential for cellular responses to biological signals. The signal transducer and activator of transcription 1 (STAT1) protein is an unclear translocating transcription regulator. Upon stimulation by interferongamma (IFN- $\gamma$ ), the STAT1 protein forms a homodimer that localizes near the nuclear membrane, where it interacts with importins. In turn, the complex binds to a subset of nuclear pore complex proteins, whereby the STAT1 homodimer translocates into the nucleus and induces gene expression. ${ }^{14-16}$ Tumor necrosis factor-alpha activates the nuclear factor kappa-light-chain enhancer of the activated B cell (NF- $\mathrm{KB})$ by releasing it from the kappa $\mathrm{B}$ inhibitor. The released NF- $\kappa \mathrm{B}$ dimer then interacts with nucleoporin- 88 to cross the nuclear pore complex barrier. ${ }^{17-20}$ After being synthesized in the nucleus, mRNA interacts with ribonucleoprotein to form the mRNP complex via the Tip-associated protein/nuclear export factor-1 pathway. The complex then interacts with the nuclear pore complex and is exported into the cytoplasm, where it is involved in protein translation. ${ }^{21,22}$ Because most physiological communications between the cytoplasm and nucleus occur primarily via the nuclear pore complex, closure of the nuclear pore complex conduit by wheat germ agglutinin, a nuclear pore complex inhibitor, or downregulation of transportin, delays or blocks nucleocytoplasmic transport (ie, nuclear RNA export and protein shuttling), suppressing cell proliferation and inducing cell death. ${ }^{23-27}$

Cell death is a critical cellular mechanism and can be divided into several types, including apoptosis, necrosis, and autophagy. Each death pathway can be identified by its specific morphological features and characteristics. ${ }^{28,29}$ When cells undergo apoptosis, or type I programmed cell death, the morphological features include nuclear condensation and formation of apoptotic bodies without a breakdown of the plasma membrane. In addition to morphological changes, apoptosis is also characterized by DNA fragmentation and activation of the caspase enzyme family. Initiator caspases, such as caspase 9, cleave the inactive proform of effector caspases (eg, caspase 3, 6, and 7) to activate them. Sequentially, cleaved (activated) effector caspases (eg, cleaved caspases 3,6 , and 7) cleave downstream protein substrates, such as poly(ADP-ribose) polymerase (PARP), triggering the apoptotic process. In contrast with apoptosis, the morphological changes in necrosis are characterized by vacuolization of the cytoplasm and breakdown of the plasma membrane, with a lack of chromatin condensation and DNA fragmentation. Autophagy is a critical mechanism that allows cells to degrade and recycle cytosolic constituents via lysosomal degradation. ${ }^{30}$ Autophagy plays dual roles, acting as executioner (cell death) or guardian (cell survival) in cancer. ${ }^{31}$ Overactivation of autophagy might lead to autophagic cell death, or type II programmed cell death, in the presence of intracellular or extracellular stresses, such as persistent nutrient starvation or continuous radiation. ${ }^{32}$ On the other hand, autophagy can rearrange the subcellular membranes to sequester cellular proteins and cytoplasmic organelles, such as mitochondria and the endoplasmic reticulum, for degradation into useful resources against apoptosis and constitutively promote cell survival. ${ }^{33,34}$ Autophagy is characterized by the presence of double-membrane or multiple-membrane cytoplasmic vesicles (autophagosomes). Microtubule-associated protein 1 light chain 3 (LC3), which is a molecular marker of the early steps of autophagy, ${ }^{35-37}$ is cleaved during the process, forming a membrane-bound $16 \mathrm{kDa}$ protein (LC3-II) from the $18 \mathrm{kDa}$ protein (LC3-I). Therefore, the LC3-II/LC3-I ratio represents the activity of autophagy. ${ }^{38}$ We studied nucleocytoplasmic transport blockade caused after longterm treatment with simian virus 40 large T-antigen (SV40) peptide-modified gold nanoparticles (GNP-PEG/SV40). This blockade killed the cells, and we sought to determine the mechanism of cell death.

\section{Materials and methods Sequential assembly of peptide-mixed monolayer gold nanoparticles}

Gold nanoparticles $(13 \mathrm{~nm})$ were synthesized using the citrate reduction method. Two surfactants for gold nanoparticle absorption were evaluated for the final nuclear localization signals of SV40 and ADV peptide-conjugated particles, ie, thiol and FITC-modified oligonucleotide (MD Bio Inc, 
Taipei, Taiwan) and poly(ethylene glycol) (PEG)-5000 (Fluka, Buchs, Switzerland). These two molecules were added to colloidal gold at a molar ratio of 200:1 (thiololigonucleotide-FITC) and 250:1 (PEG-5000) at $4{ }^{\circ} \mathrm{C}$ for 16 hours. Oligonucleotide-conjugated gold nanoparticles were then admixed with $10 \mathrm{mM} \mathrm{PB} / 0.1 \mathrm{M} \mathrm{NaCl}$ at $4^{\circ} \mathrm{C}$ for another 16 hours, which made the oligonucleotide stand outward from the gold core with high surface coverage, exposing the FITC dye. The excess oligonucleotide was removed by centrifugation at $10,000 \times \operatorname{rcf}$ for 20 minutes and washed twice with $1 \times$ phosphate-buffered saline at $4^{\circ} \mathrm{C}$. The washed gold nanoparticles were mixed with SV40 and ADV peptide at a molar ratio of 1:500 and maintained at $4^{\circ} \mathrm{C}$ for 16 hours. The PEGylated gold nanoparticles were mixed with two $5^{\prime}$ end cysteine-modified nuclear localization signal peptides at a molar ratio of 1:1000. The two particle mixtures were purified by centrifugation and washed twice with $1 \times$ phosphate-buffered saline. Ultraviolet-visible absorption density (ND-1000, NanoDrop Technologies, Wilmington, DE) was measured to determine the final concentration of conjugated gold nanoparticles. The physical properties of the peptide-modified gold nanoparticles, specifically zeta potential and submicron particle size, were identified using a particle size analyzer (DelsaNano C, Beckman Coulter Inc, Fullerton, CA) to confirm successful conjugation.

\section{Cell lines, cell culture, and reagents}

Human cervical carcinoma HeLa and SiHa cells were cultured in Dulbecco's modified Eagle medium (DMEM) containing $10 \%$ fetal bovine serum and $1 \%$ antibiotics (penicillin, streptomycin, and amphotericin B) at $37^{\circ} \mathrm{C}$ in a humidified $5 \% \mathrm{CO}_{2}$ incubator. When cells reached $80 \%$ confluence, they were trypsinized and plated into different plates or dishes for experiments. Cells were incubated with various concentrations of peptide-modified gold nanoparticles or wheat germ agglutinin (SI-L0636, Sigma, St Louis, MO) for different time periods, washed three times with phosphate-buffered saline, and harvested by trypsinization at the end of the incubation period.

\section{Transmission electron microscopy}

HeLa cells were incubated with peptide-modified gold nanoparticles at a concentration of $7.5 \mathrm{nM}$ for 24-96 hours, washed three times with cold phosphate-buffered saline, and fixed with $2 \%$ paraformaldehyde and $2.5 \%$ glutaraldehyde for 30 minutes at room temperature. Cells were post-fixed with $1 \%$ osmium tetroxide in $0.1 \mathrm{M}$ sodium cacodylate buffer ( $\mathrm{pH}$ 7.2) for one hour and washed and dehydrated in graded concentrations of ethanol $(50 \%, 70 \%$, and $100 \%)$ and propylene oxide. The samples were then embedded in Epon (Fluka) and cut into ultrathin sections. Thin sections $(80 \mathrm{~nm})$ were collected on copper transmission electron microscopy (TEM) grids and stained with 5\% uranyl acetate for 20 minutes and lead citrate for 10 minutes. The grids were analyzed by TEM (JEOL-1200, Tokyo, Japan) at an accelerating voltage of $80 \mathrm{kV}$.

\section{Immunofluorescent staining and confocal laser microscopy}

To analyze the intracellular localization (trajectories) of the peptide-modified gold nanoparticles, the cells were grown in six-well chamber slides (BD, Bedford, MA). After overnight incubation, the cells were fixed and their nuclei stained with 4',6-diamidino-2-phenylindole (DAPI). For total RNA staining, acridine orange was added at a concentration of $5 \mu \mathrm{g} / \mathrm{mL}$ and allowed to incubate for 2-5 minutes at room temperature. The cells were washed with fresh phosphatebuffered saline and imaged immediately. For immunofluorescence, the cells were fixed with $4 \%$ paraformaldehyde in phosphate-buffered saline for 10 minutes, permeabilized with $0.05 \%$ Triton-X for 10 minutes at room temperature, and washed three times with phosphate-buffered saline. Antibodies were diluted in blocking buffer (5\% goat serum in phosphate-buffered saline). Cells were incubated with primary antibodies against STAT1 (610115, BD Bioscience, Lexington, KY), NF-кB (sc-372, Santa Cruz Biotechnology Inc, Santa Cruz, CA), or nuclear pore complex protein (Mab414, ab24609, Abcam, Cambridge, MA) overnight at $4^{\circ} \mathrm{C}$ and then washed three times with phosphate-buffered saline. The cells were incubated with Alexa Fluor 594conjugated secondary antibody (Invitrogen, Eugene, OR) for 60 minutes at room temperature, and then washed four times with phosphate-buffered saline. Fluorescent and cellular morphology images were taken with a digital camera and a charge-coupled device image sensor on an Olympus FluoView ${ }^{\mathrm{TM}}$ FV1000 microscope equipped with a differential interference contrast channel (FV1000, Olympus, Tokyo, Japan). All channels were recorded in a sequential order to avoid emission crosstalk.

\section{Cytotoxicity assay}

$\mathrm{HeLa}$ or SiHa cells were seeded into 24-well plates at a density of $2 \times 10^{4}$ cells/well and incubated for 24 hours. Peptide-modified gold nanoparticles $(7.5 \mathrm{nM})$ and wheat germ agglutinin $(5 \mu \mathrm{g} / \mathrm{mL})$ were added to the cells for 6 , 
$24,48,72$, or 96 hours. In other experiments, cells were treated with a concentration range of peptide-modified gold nanoparticles $(5.0,7.5,10$, or $25 \mathrm{nM})$ or wheat germ agglutinin $(0.05,0.5,5.0,25$, or $50 \mu \mathrm{g} / \mathrm{mL})$ for 24 hours. An [3-(4,5-dimethylthiazol-2-yl)-2,5-diphenyltetrazolium bromide] (MTT) assay was used to determine cytotoxicity. In brief, $300 \mu \mathrm{L}$ of MTT reagent was added to each well and incubated at $37^{\circ} \mathrm{C}$ for 30 minutes. After incubation, dimethyl sulfoxide solution was used to dissolve the formazan crystals. Optical density was measured at a wavelength of $490 \mathrm{~nm}$ in a 96-well microplate reader (Sunrise, Tecan Ltd, Mannedorf, Switzerland) and the percentage of viable cells calculated.

\section{Determination of cell apoptosis and necrosis}

Treated cells were washed twice with cold phosphatebuffered saline and resuspended in $1 \times$ binding buffer at a concentration of $1 \times 10^{6}$ cells $/ \mathrm{mL}$. A $100 \mu \mathrm{L}$ aliquot of the solution was transferred to a $5 \mathrm{~mL}$ culture tube and $5 \mu \mathrm{L}$ of annexin V-Cy 5 plus propidium iodide (BD, San Diego, $\mathrm{CA}$ ) added. The cells were gently vortexed and incubated for 15 minutes at room temperature in the dark. After incubation, $400 \mu \mathrm{L}$ of $1 \times$ binding buffer was added into each flow tube and analyzed within one hour by flow cytometry. Cells that were annexin $\mathrm{V}$-negative and propidium iodide-negative were considered viable cells. Cells that were annexin V-positive and propidium iodide-negative were considered early-stage apoptotic cells. Cells that were annexin V-positive and propidium iodide-positive were considered late-stage apoptotic cells. Cells that were annexin V-negative and propidium iodide-positive were considered necrotic cells.

\section{Western blot analysis}

After treatment, cells were washed twice with phosphatebuffered saline and harvested using radioimmunoprecipitation assay (RIPA) cell lysis buffer (50 mM Tris, $150 \mathrm{mM} \mathrm{NaCl}$, $1 \%$ nonyl phenoxypolyethoxylethanol [NP-40], 0.5\% sodium deoxycholate, $0.1 \%$ sodium dodecyl sulfate) and $1 \times$ protease inhibitor cocktail. Equal amounts of protein were subjected to $10 \%-15 \%$ sodium dodecyl sulfate-polyacrylamide gel electrophoresis and electrotransferred onto polyvinylidene fluoride membrane (Millipore Corporation, Billerica, MA). Nonspecific binding sites were eliminated using 5\% fat-free milk in Tris-buffered saline with $0.1 \%$ Tween 20 at room temperature for one hour. The membranes were incubated with primary antibody at $4{ }^{\circ} \mathrm{C}$ for 16 hours. The following primary antibodies were used: $\beta$-actin (43 kDa), Beclin-1 (60 kDa), LC3 (16 kDa and $18 \mathrm{kDa})$, activated caspase 3
(19 kDa), and caspase 9 (37 kDa). After incubation, the membranes were washed three times with Tris-buffered saline with $0.1 \%$ Tween 20 and reacted with the corresponding peroxidase-conjugated antirabbit or antimouse secondary antibodies at room temperature for one hour. Protein signals were detected by chemiluminescence using the horseradish peroxidase substrate, Luminol (Millipore) and visualized with a UVP imaging system (UVP, Upland, CA).

\section{Transfection with plasmid encoding EGFP-LC3}

Plasmid encoding enhanced green fluorescent protein (EGFP)-LC3 was a gift from Professor Liu (Department of Microbiology and Immunology, National Chung Kung University, Tainan, Taiwan). Cells grown at $80 \%$ confluence were transiently transfected with $1 \mu \mathrm{g} / \mathrm{mL}$ of EGFP-LC3 plasmid using Lipofectamine 2000 (Invitrogen) according to the manufacturer's instructions. After 24 hours of transfection, cells were treated with $5 \mathrm{mM} 3$-methyl adenine for another 24 hours to inhibit the formation of autophagosomes. EGFP-LC3-positive punctate were then detected by confocal laser microscopy as described above.

\section{Small hairpin RNA lentiviral production for Beclin-I knockdown}

Lentiviral vectors containing Beclin-1 (BECN1) small hairpin RNA were obtained from the National RNAi Core Facility (Academia Sinica, Taipei, Taiwan) and prepared in accordance with standard protocols. Briefly, $3 \times 10^{6}$ 293 T cells were seeded in a $10 \mathrm{~cm}$ dish. After 24 hours, cells were cotransfected with $5 \mu \mathrm{g}$ pLKO. 1shRNA, $5 \mu \mathrm{g}$ pCMV $\triangle$ R8.91, and 0.5 $\mu \mathrm{g}$ pMD. G plasmids using Lipofectamine 2000 (Invitrogen). After transfection, we changed the medium to remove the transfection reagents and collected the virus 48 hours later and passed it through $0.45 \mu \mathrm{m}$ filters. Cells were infected with lentivirus (multiplicity of infection $=5$ ) in the presence of Polybrene ${ }^{\circledR} 8 \mu \mathrm{g} / \mathrm{mL}$. Forty-eight hours after infection, the cells were treated with puromycin $1 \mu \mathrm{g} / \mathrm{mL}$ to select puromycin-resistant clones. The BECN1 small hairpin RNA target sequence was 5'-CCGACTTGTTCCTTACGGAAA-3'.

\section{Statistical analysis}

All experiments were repeated at least three times. The data are presented as the mean \pm standard error of the mean. Statistical analysis was performed using the Student's $t$-test (two-tailed). $P<0.05$ was considered to be statistically significant. 


\section{Results}

\section{Effect of long-term treatment with GNP-PEG/SV40 on cells}

We assembled cysteine-terminated ADV and SV40 nuclear localization signal peptides (Table 1) with PEGylated gold nanoparticles using a sequential absorption method. ${ }^{39}$ Submicron particle size analysis revealed that the hydrodynamic size of the particles increased from $14.8 \pm 3.32 \mathrm{~nm}$ to $39.07 \pm 2.46 \mathrm{~nm}$ and $31.57 \pm 0.93 \mathrm{~nm}$ after assembling with ADV and SV40 peptides, respectively. The negative surface charge of the gold nanoparticles $(-32.35 \pm 1.7 \mathrm{mV})$ increased to $-8.23 \pm 0.68 \mathrm{mV}$ and $-9.28 \pm 1.32 \mathrm{mV}$ when conjugated with the positively charged ADV and SV40 peptides, respectively. The data indicate successful conjugation of GNP-PEG/ADV and GNP-PEG/SV40 (Table 2).

$\mathrm{HeLa}$ and SiHa cells were treated with peptide-modified gold nanoparticles $(7.5 \mathrm{nM})$ for various time intervals, and cellular localization of the gold nanoparticles was determined by coanalysis of data from a laser confocal microscope equipped with a differential interference contrast (DIC) channel and TEM. In HeLa cells, GNP-PEG/SV40 reached and clustered around the cytoplasmic side of the nuclear membrane after 24 hours of treatment, as revealed by confocal microscopy. In contrast, unmodified gold nanoparticles dispersed in the cytoplasm (Figure 1A). The location of the gold nanoparticles in cells was also visualized by differential interference contrast microscopy because of the high contrast gold core. GNP-PEG/SV40 localized around the nucleus, and GNP-PEG dispersed in the cytoplasm. Some GNP-PEG/ ADV particles were found in the nucleus (Figure 1B, arrow), but no perinuclear accumulation of the particles was seen. TEM images revealed that the nuclear pores (Figure 1C, arrows) and laminar structure (dark region in vicinity of the nuclear pore) were intact in untreated HeLa cells. After treatment with GNP-PEG/SV40 for 24 hours, the nuclear pore became obscured. The nuclear membrane pattern became linear (poreless nuclei) after 48 and 72 hours of treatment with GNP-PEG/SV40 (Figure 1C). In contrast, the nuclear pore structure was still intact in HeLa cells after long-term treatment with GNP-PEG/ADV (Figure S1). In SiHa cells,

Table I Peptide sequence used for assembling gold nanoparticlePEG conjugates

\begin{tabular}{lll}
\hline Abbreviation & Peptide sequence & Origin peptide \\
\hline SV40 & CGGGPKKKRKVGG & SV40 large T NLS \\
ADV & CGGFSTSLRARKA & Adenoviral NLS \\
\hline
\end{tabular}

Abbreviations: ADV, adenovirus; NLS, nuclear localization signal; SV40, simian virus 40 large T NLS peptide; PEG, poly(ethylene glycol).
Table 2 Characterization of gold nanoparticles before and after peptide modification

\begin{tabular}{lcc}
\hline & $\begin{array}{l}\text { Hydrodynamic } \\
\text { diameter }(\mathbf{n m})\end{array}$ & $\begin{array}{l}\text { Zeta potential } \\
(\mathbf{m V})\end{array}$ \\
\hline GNP & $14.8 \pm 3.32$ & $-32.35 \pm 1.7$ \\
GNP-PEG & $26.57 \pm 0.15$ & $-12.34 \pm 0.81$ \\
GNP-PEG/ADV & $39.07 \pm 2.46$ & $-8.23 \pm 0.68$ \\
GNP-PEG/SV40 & $31.57 \pm 0.93$ & $-9.28 \pm 1.32$ \\
\hline
\end{tabular}

Notes: Molecular weights I27I.5 Da (SV40 peptide) and I353.5 Da (ADV peptide). Theoretical pl 10.48 (SV40 peptide) and 10.86 (ADV peptide). GNP-PEG/ADV and GNP-PEG/SV40 are peptide-modified GNPs. The modification of GNPs with SV40 and ADV peptide slightly increased the zeta potential at physiological $\mathrm{pH}$ (6.8). Following the different peptide modifications, the hydrodynamic diameter increased by $24.3 \mathrm{~nm}$ and $16.8 \mathrm{~nm}$, respectively, when compared with GNPs alone, indicating successful modification of the GNPs.

Abbreviations: GNPs, gold nanoparticles; PEG, poly(ethylene glycol); ADV, adenovirus NLS peptide; SV40, simian virus 40 large T NLS peptide; NLS, nuclear localization signal.

GNP-PEG/SV40 accumulated focally in the perinuclear area, whereas GNP-PEG/ADV accumulated inside the nuclei (Figure S2). The nuclear pore complex structure was also revealed by immunofluorescence probed with $\alpha$-nuclear pore complex antibody. HeLa cells treated with GNP-PEG and GNP-PEG/ ADV exhibited well preserved nuclear rim staining (Figure $2 \mathrm{~A}-\mathrm{C}$ ), indicating that the nuclear pore complex structure was intact. However, in HeLa cells treated with GNP-PEG/ SV40, nuclear rim staining was lost (Figure 2D). The findings from the immunofluorescence study were consistent with the TEM images. The long-term treatment of HeLa cells with GNP-PEG/SV40 resulted in morphological changes in the nuclear pore complex.

\section{Long-term treatment with GNP-PEG/ SV40 blocked nucleocytoplasmic transport}

We speculated that perinuclear accumulation of GNP-PEG/ SV40 and loss of nuclear pore complex structure would result in blockade of nucleocytoplasmic transport. Therefore, we studied the subcellular distribution of total RNA in HeLa cells using acridine orange staining and treatment with $7.5 \mathrm{nM}$ GNP-PEG, GNP-PEG/ADV, or GNP-PEG/SV40 for various time intervals. The RNA was evenly distributed in the nucleus and cytoplasm at baseline and after treatment for 3 hours (Figure 3A). After additional treatment with GNP-PEG or GNP-PEG/ADV for 6 or 9 hours, the RNA distribution did not change. However, the RNA was confined within the nucleus (RNA was overlapped with the DAPI) and unable to reach the cytoplasm after treatment with GNP-PEG/SV40 (Figure 3B and C). In addition, nuclear RNA isolation followed by quantitative reverse transcriptase polymerase chain reaction confirmed accumulation of tRNA ${ }^{\text {Lys }}$ in the nuclei of cells treated with GNP-PEG/SV40 (1.61 \pm 0.025 fold) and 
A
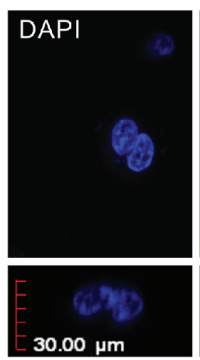

B

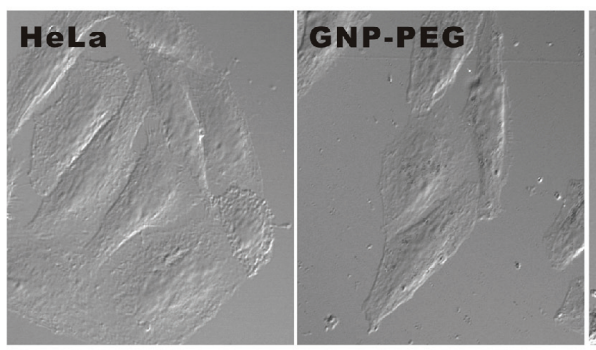

C
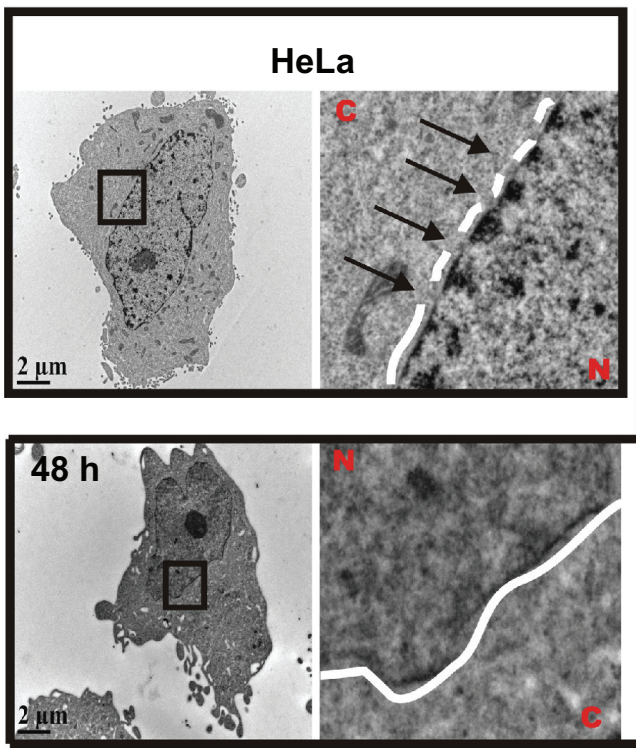

GNP-PEG
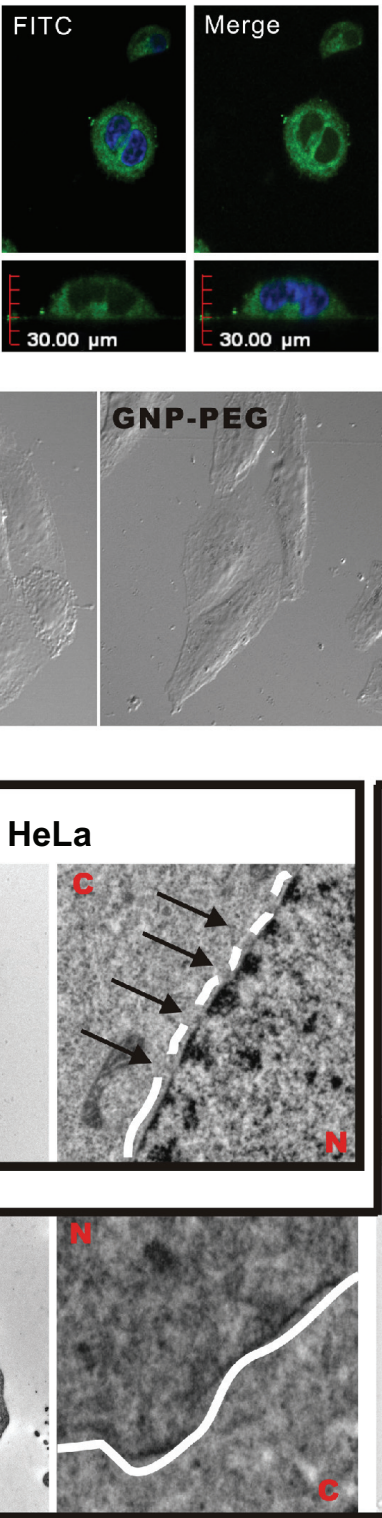
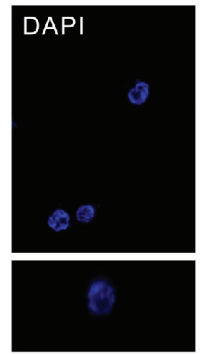

GNP-PEG/SV40
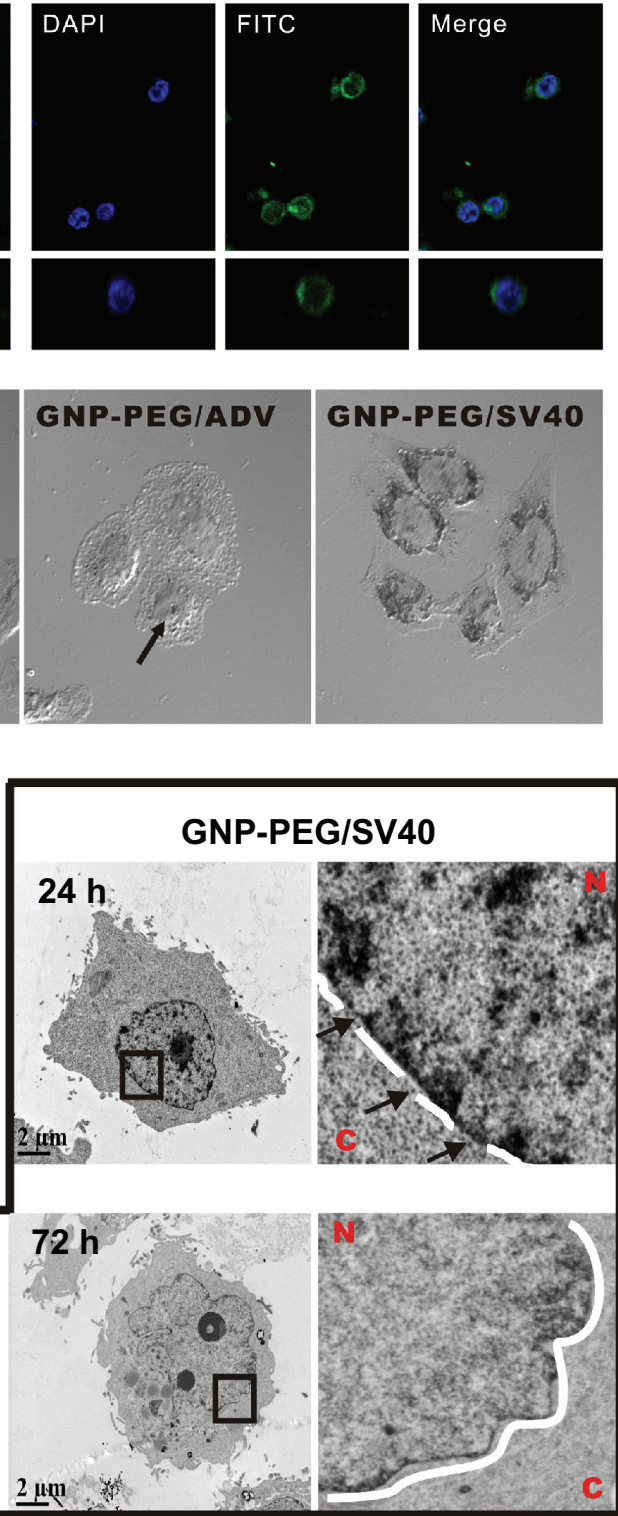

Figure I Localization of GNP-PEG/SV40 at the nuclear membrane and morphological changes to the nuclear pore complex. (A) A fluorescent probe $($ I $0 \times$ thymin-FITC) was intermixed with PEG and signal peptides (SV40 and ADV) on the surface of gold nanoparticles and visualized by confocal microscopy (green color). GNP-PEG/SV40 accumulated around the nuclear membrane ( $Z$ axis section), whereas unmodified particles were distributed in the cytoplasm after 24 hours of treatment. (B) Due to the high contrast properties of the gold nanoparticles, accumulated particles (dark spots) were observed for the differential interference contrast channel with the same cellular distribution as shown by laser confocal microscopy. (C) Transmission electron microscopic images of the treated cells show GNP-PEG/SV40 blocked nuclear pore complex conduits with increasing time, compared with the untreated control cells, in which the nuclear pore complexes are open and unobstructed. The nuclear pores (arrows) and lamina are clearly shown in the image. Concentration of peptide-modified gold nanoparticles, $7.5 \mathrm{nM}$.

Abbreviations: ADV, adenovirus; DAPI, 4',6-diamidino-2-phenylindole; FITC, fluorescein isothiocyanate; GNP, gold nanoparticle; PEG, poly(ethylene glycol); SV40, simian virus 40 large T antigen; N, nucleus; C, cytoplasm.

with wheat germ agglutinin $(5 \mu \mathrm{g} / \mathrm{mL}, 2.26 \pm 0.182$ fold; $10 \mu \mathrm{g} / \mathrm{mL}, 3.374 \pm 0.096$ fold) compared with control cells (Figure S3).

Next, we studied whether the shuttling of signaling proteins from the cytoplasm to the nucleus was prevented by nucleocytoplasmic transport blockade. We chose two common signaling proteins, STAT1 and NF- $\kappa B$, for the study.
In GNP-PEG/ADV-treated HeLa cells, IFN- $\gamma$ and tumor necrosis factor-alpha induced nuclear translocation of STAT1 and NF- $\kappa \mathrm{B}$ proteins, respectively (Figure 4A). However, in GNP-PEG/SV40-treated HeLa cells, STAT1 and NF- $\kappa B$ proteins remained in the cytoplasm after stimulation by IFN- $\gamma$ and tumor necrosis factor-alpha, respectively (Figure 4B). These findings indicate that the shuttling of signaling 
A
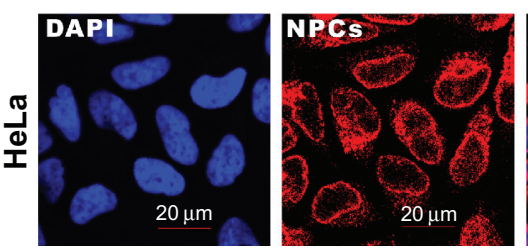

B

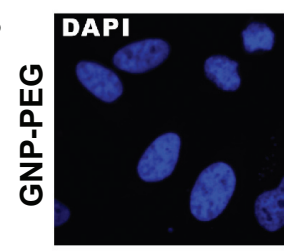

C

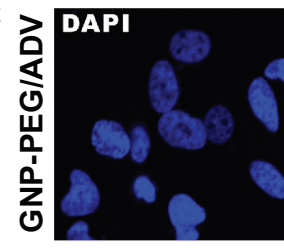

D

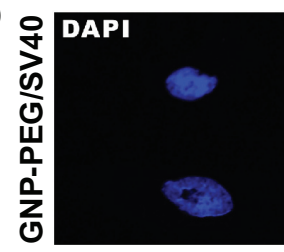

\section{NPGs}

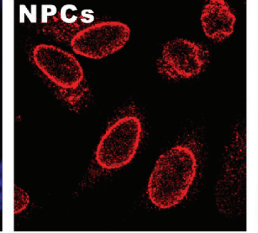

NPCs

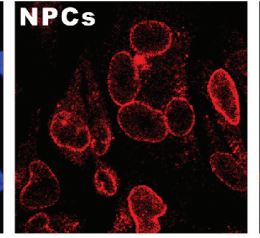

NPGs

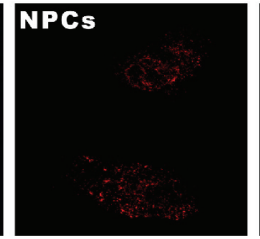

Figure 2 Diminished nuclear pore complex structure after GNP-PEG/SV40 treatment for 72 hours. HeLa cells and nanoparticle-treated HeLa cells were doublelabeled with DAPI and $\alpha$-nuclear pore complex antibody (Mab4|4), and analyzed by immunofluorescence microscopy. Nuclear rim staining was found in (A) HeLa, (B) GNP-PEG, and (C) GNP-PEG/ADV control cells. The intensity of nuclear rim staining was dramatically reduced and diminished after treatment with (D) GNPPEG/SV40. Concentration of peptide-modified gold nanoparticles was $7.5 \mathrm{nM}$. Abbreviations: DAPI, 4',6-diamidino-2-phenylindole; GNP, gold nanoparticle NPC, nuclear pore complex; PEG, poly(ethylene glycol); SV40, simian virus 40 large $\mathrm{T}$ antigen.

proteins from the cytoplasm to nucleus was blocked. Thus, blockade of nucleocytoplasmic transport led to retention of newly synthesized RNA inside the nucleus and prevented the STAT1 and NF- $\mathrm{kB}$ signaling proteins from translocating into the nucleus.

\section{Effect of long-term nucleocytoplasmic transport blockade by GNP-PEG/SV40}

To study whether long-term nucleocytoplasmic transport blockade might influence cell survival, we treated HeLa cells with various concentrations $(5,7.5,10$, and $25 \mathrm{nM})$ of GNP-PEG, GNP-PEG/ADV, or GNP-PEG/SV40 for 24 hours. GNP-PEG/SV40 decreased cell survival to a greater extent than the other two particle types (Figure 5A). All nanoparticles caused significant cell death beyond a concentration of $25 \mathrm{nM}$. Cell death began to increase among GNP-PEG/SV40-treated cells at 6 hours $(12.2 \% \pm 4 \%)$ and gradually increased in a time-dependent manner, with $43.22 \% \pm 0.2 \%, 57.96 \% \pm 0.61 \%$, and $86.65 \% \pm 0.24 \%$ of cells being dead at 24 hours, 48 hours, and 96 hours, respectively. The cytotoxicity caused by GNP-PEG and GNP-PEG/ADV particles at a concentration of $7.5 \mathrm{nM}$ was mild, ie, $13.73 \% \pm 1.7 \%$ and $25.15 \% \pm 4 \%$ for GNP-PEG and GNP-PEG/ADV, respectively, after 96 hours of treatment (Figure 5B). The difference in cytotoxic activity between GNP-PEG/ADV and GNP-PEG/SV40 nanoparticles is not due to variation in cellular uptake because the quantity of intracellular nanoparticles measured by atomic absorption spectrometry in HeLa cells was similar for GNP-PEG/ ADV (4.041 $\pm 0.136 \mu \mathrm{g} \mathrm{Au} / 10^{5}$ cells) and GNP-PEG/SV40 $\left(4.358 \pm 0.253 \mu \mathrm{g} \mathrm{Au} / 10^{5}\right.$ cells, Figure S4).

After treatment with GNP-PEG/SV40, TEM imaging showed multiple small vesicles inside the cytoplasm; however, the cellular compartment was still intact in the early stages (24 hours, Figure 5C). After long-term nucleocytoplasmic transport blockade ( 72 hours), cellular organelles were engulfed by multimembrane structures, suggesting the existence of autophagosomes (Figure 5D). Some of the autophagosomes fused with endosomal or lysosomal vesicles to generate autolysosomes, which degraded the contents into their biosynthetic components (Figure 5D). Thus, long-term nucleocytoplasmic transport blockade by cell death induced by GNP-PEG/SV40 in a time-dependent manner in HeLa cells.

\section{Mechanism of cell death induced by nucleocytoplasmic transport blockade}

To elucidate the mechanism of cell death after long-term nucleocytoplasmic transport blockade induced by GNPPEG/SV40, we studied apoptotic mechanisms in HeLa cells. Using antibodies that specifically recognized the cleaved forms of caspases 3 and 9, we found that the cleaved forms did not increase after treatment with $7.5 \mathrm{nM}$ GNP-PEG/ SV40 for 24, 48, 72, or 96 hours (Figure S5). The results were similar to those of untreated, GNP-PEG-treated, and GNP-PEG/ADV-treated cells. Apoptotic cells were also characterized by double annexin V-positive and propidium iodide-negative expression in flow cytometric analysis. Late apoptotic or necrotic cells were characterized by annexin V-positive and propidium iodide-positive expression. In the presence of the anticancer drug, cisplatin ( $50 \mu \mathrm{M}, 24$ hours), the predominant cell population $(89.4 \%)$ was annexin V-positive and propidium iodide-negative, representing apoptotic cells. At various concentrations of GNP-PEG, GNP-PEG/ADV, or GNP-PEG/SV40 (1.0 to $7.5 \mathrm{nM})$ and in untreated cells, no increase in annexin V-positive and propidium iodide-negative cells (less than $1 \%$ ) or annexin V-positive and propidium iodide-positive cells (less than 4\%) 
A

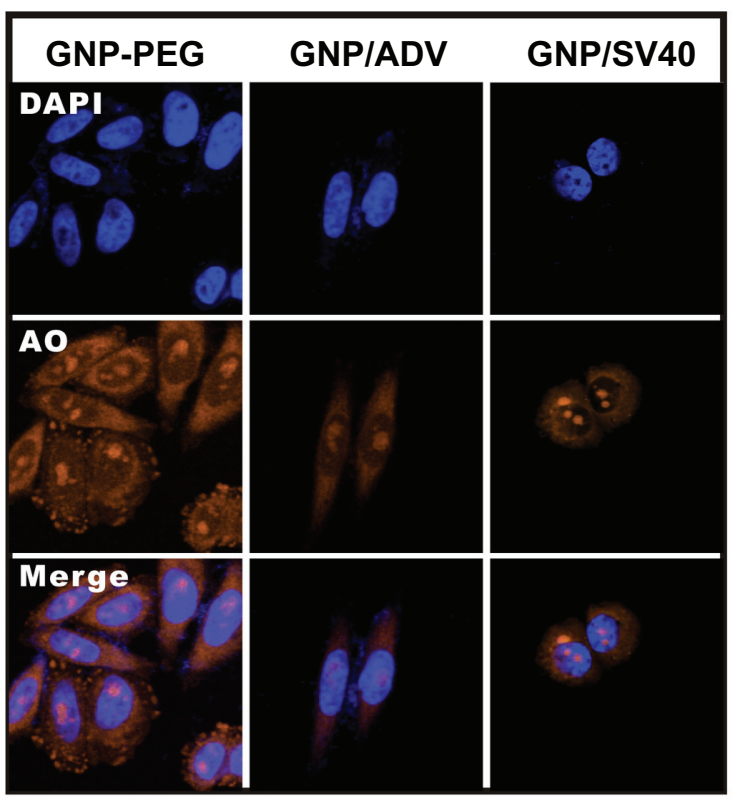

B

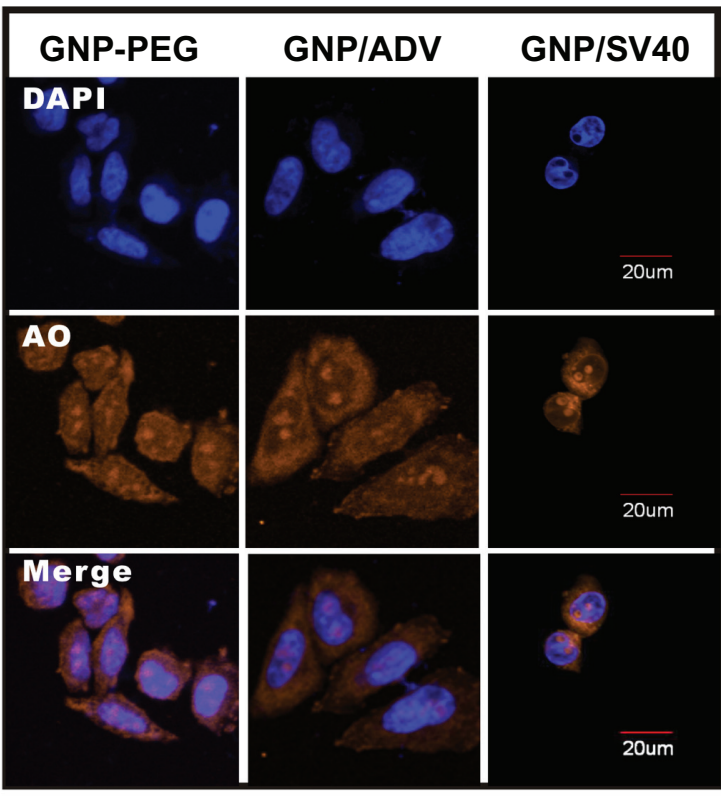

C

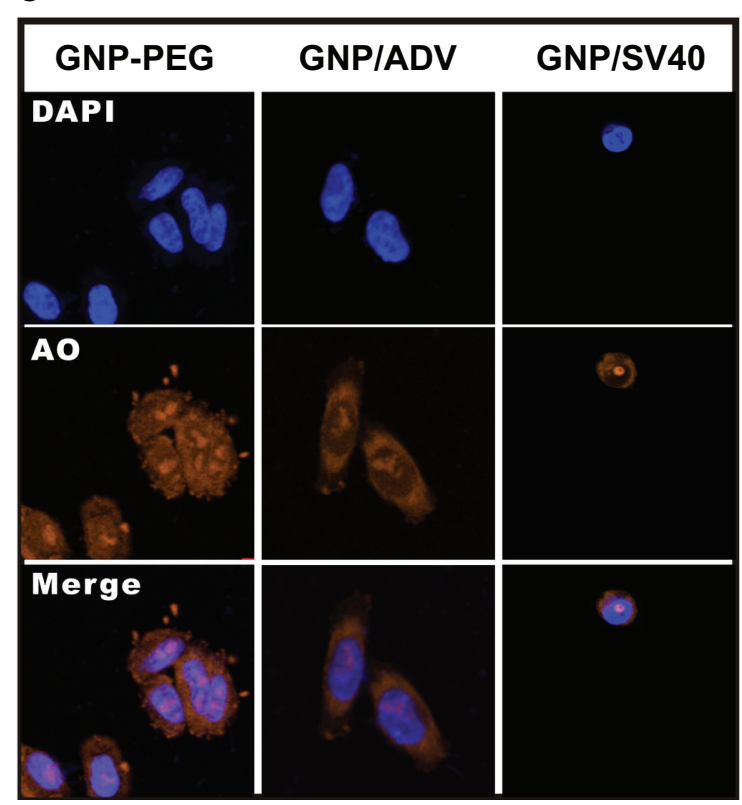

Figure 3 Subcellular distribution of total RNA in cells treated with GNP-PEG, GNP-PEG/ADV, and GNP-PEG/SV40 for (A) 3, (B) 6, and (C) 9 hours. RNA was stained with acridine orange (yellow color) and observed by confocal microscopy. Total RNA was gradually restricted inside the nucleus (DAPI, blue color) with GNP-PEG/SV40 treatment, but not with GNP-PEG or GNP-PEG/ADV (throughout the cytoplasm and nucleus).

Abbreviations: ADV, adenovirus; DAPI, 4',6-diamidino-2-phenylindole; GNP, gold nanoparticle; PEG, poly(ethylene glycol); SV40, simian virus 40 large T antigen.

was measured (Figure S6A). Neither annexin V-positive and propidium iodide-negative nor annexin $\mathrm{V}$-positive and propidium iodide-positive cell populations increased when cells were treated with $7.5 \mathrm{nM}$ GNP-PEG, GNP-PEG/ADV, or GNP-PEG/SV40 for 24 hours to 96 hours (Figure S6B). Thus, no significant late apoptosis or necrosis was induced by GNP-PEG/SV40.
Because cytoplasmic vesicles (autophagosomes and autolysosomes) were induced by GNP-PEG/SV40, we assessed the expression of LC3, a common molecular marker of autophagy, in HeLa cells. LC3-II protein was more abundant in the GNP-PEG/SV40-treated cells. When defining autophagic activity as the percentage of membrane-bound $16 \mathrm{kDa}$ protein (LC3-II) with respect to the percentage 
A

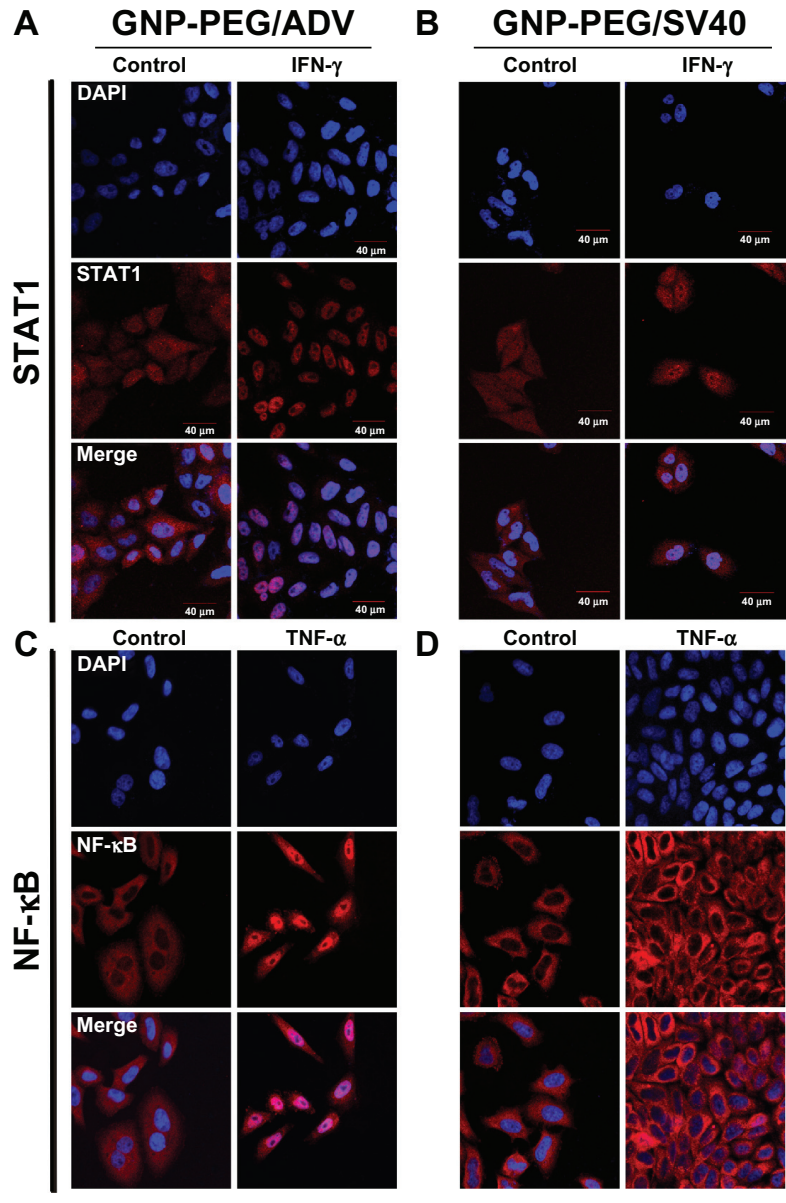

Figure 4 Cellular transportation of shuttle protein STATI and transcription regulator NF-KB (red color: Alexa Fluor 594-conjugated rabbit secondary antibody) were both restricted to the cytoplasm due to nucleocytoplasmic transport blockade. (A) IFN- $\gamma$ and tumor necrosis factor-alpha were used to stimulate the translocation of cytoplasmic STATI and NF- $\mathrm{KB}$ into the nucleus, respectively, upon GNP-PEG/ADV administration. (B) In contrast, both signaling proteins remained in the cytoplasm and nucleocytoplasmic transport was blocked by GNP-PEG/ SV40, abolishing the related signal cascade. Concentration of peptide-modified gold nanoparticles was $7.5 \mathrm{nM}$.

Abbreviations: ADV, adenovirus; DAPI, 4',6-diamidino-2-phenylindole; GNP, gold nanoparticle; PEG, poly(ethylene glycol); SV40, simian virus 40 large $T$ antigen; IFN- $\gamma$, interferon gamma; STATI, signal transducer and activator of transcription I; $\mathrm{NF}-\mathrm{kB}$, nuclear factor kappaB; TNF- $\alpha$, tumor necrosis factor alpha.

of $\beta$-actin per lane, an increase in autophagic activity was observed in the GNP-PEG/SV40-treated cells at $5.0 \mathrm{nM}$ and $7.5 \mathrm{nM}$ (Figure 6A). Autophagic activation increased by approximately $24 \%$ and $84 \%$ at 24 hours and 96 hours after treatment, respectively (Figure 6B). To confirm the appearance of autophagy, HeLa cells were transfected with plasmids transiently expressing the chimeric fluorescent protein, EGFP-LC3, before treatment with peptide-modified gold nanoparticles (7.5 nM) for 48 hours. Autophagy activation induced EGFP-LC3 aggregation (green dots) in the cytoplasm. The number of EGFP-LC3-positive punctates increased significantly in the GNP-PEG/SV40treated cells compared with the other three treatments. The increase in EGFP-LC3 aggregation induced by GNP-PEG/ SV40 was blocked by the addition of 3-methyl adenine (3MA), an autophagy inhibitor, to the cell culture medium (Figure 6C).

We also tested the effect of different peptide-modified gold nanoparticles in SiHa cells, which showed only nuclear localization (Figure S2). An autophagic response was not induced in GNP-PEG, GNP-PEG/ADV, or GNP-PEG/SV40-treated SiHa cells after treatment with various concentrations $(1.0-7.5 \mathrm{nM})$, as evidenced by unchanged LC3-II levels (Figure S7A). Again, we observed no enhancement of LC3-II levels from 24 hours to 96 hours in the GNP-PEG, GNP-PEG/ADV, and GNPEG/SV40-treated (7.5 nM) SiHa cells (Figure S7B). Accordingly, autophagy, but not apoptosis or necrosis, was induced in the cells with perinuclear accumulation of peptide-modified gold nanoparticles after long-term treatment.

\section{Cellular effect of nucleocytoplasmic transport blockage by the NPC inhibitor WGA}

The blockade of nucleocytoplasmic transport by wheat germ agglutinin was similar to that for SV40 peptide-modified gold nanoparticles in HeLa cells. In the MTT assay, the cytotoxicity of wheat germ agglutinin $5 \mu \mathrm{g} / \mathrm{mL}$ began to increase at 24 hours $(17.7 \% \pm 1.5 \%)$ and gradually increased thereafter in a time-dependent manner, with $55.5 \% \pm 4.7 \%$, $67.9 \% \pm 7.4 \%$, and $88.5 \% \pm 5.5 \%$ of cells dead at 48 hours, 72 hours, and 96 hours, respectively, which was similar to that found for treatment with GNP-PEG/SV40 (12.2\% $\pm 4 \%$ to $86.65 \% \pm 0.24 \%$ ) in HeLa cells (Figure 7A). Elevation of LC3-II ranged from $117 \%$ to $200 \%$ upon treatment with $5.0,25$, and $50 \mu \mathrm{g} / \mathrm{mL}$ of wheat germ agglutinin, and the protein was continuously expressed from 24 hours to 96 hours with $5.0 \mu \mathrm{g} / \mathrm{mL}$ wheat germ agglutinin treatment (Figure 7B). Furthermore, in wheat germ agglutinin-treated SiHa cells, autophagy increased significantly at concentrations of 5.0, 25, and $50 \mu \mathrm{g} / \mathrm{mL}$ and lasted from 24 hours to 96 hours in HeLa cells (Figure S8). The autophagy response was fully induced when nucleocytoplasmic transport was blocked by the nuclear pore complex inhibitor wheat germ agglutinin.

\section{GNP-PEG/SV40-induced autophagy acts on cell death, not survival}

To determine whether induction of autophagy by GNPPEG/SV40 is a mechanism of survival or of death, we inves- 

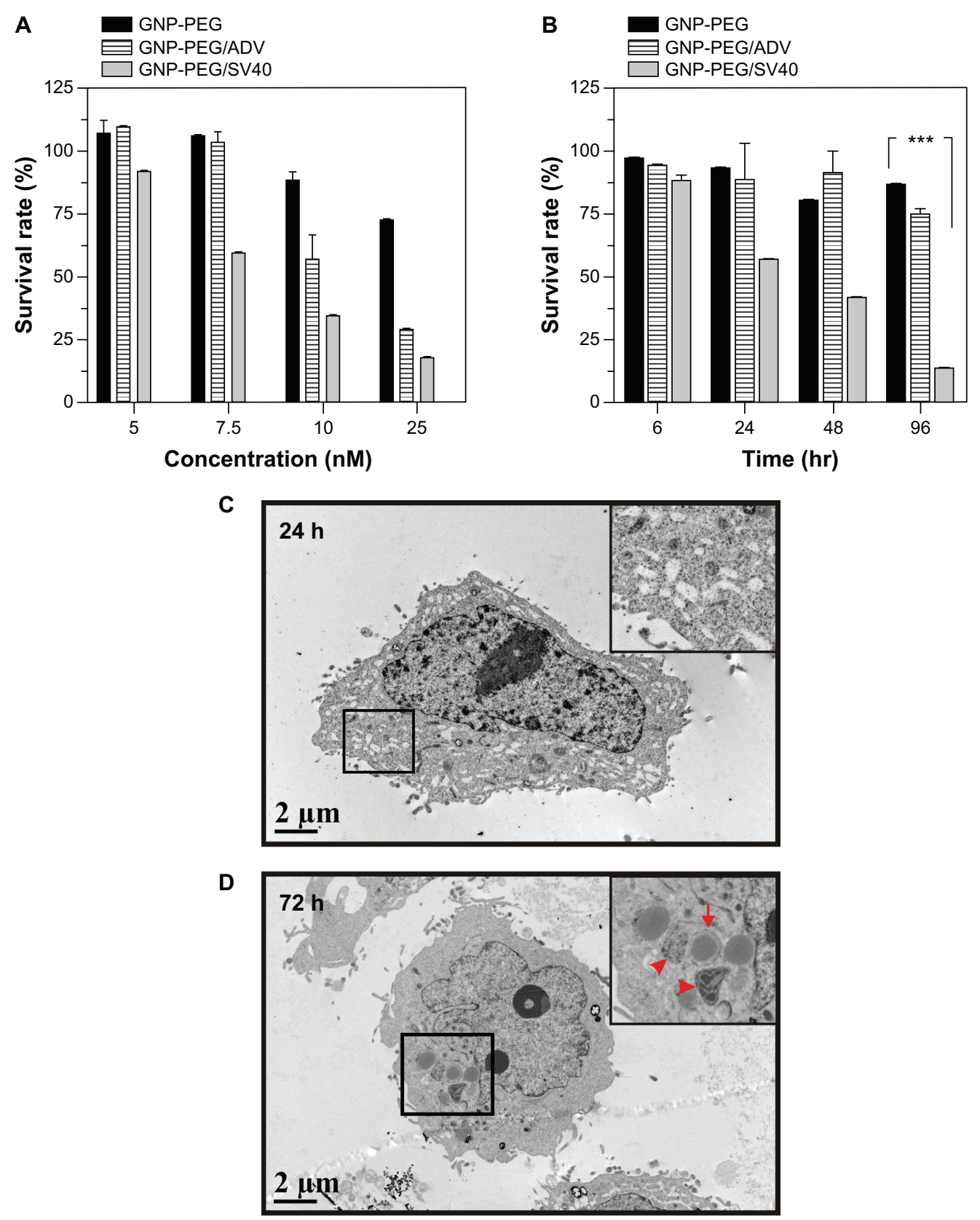

Figure 5 Cell death was caused by administration of GNP-PEG/SV40 at (A) different gold concentrations (B) for different time periods. Transmission electron microscopic images of GNP-PEG/SV40-treated cells exhibiting small vesicles at (C) 24 and (D) 72 hours, which eventually caused the dissociation of cellular apparatus by digestion vesicles, such as autophagosomes (e-al) (arrows) and autolysosomes (d-al) (arrow head).

Abbreviations: ADV, adenovirus; GNP, gold nanoparticle; PEG, poly(ethylene glycol); SV40, simian virus 40 large T antigen.

tigated the effects of GNP-PEG/SV40 on cell viability using small hairpin RNA to knockdown BECN1, an initiated protein required for autophagosome formation, in HeLa cells. The expression of BECN1 protein was successfully knocked down (Figure 8A) and the ratio of LC3-II formation was not increased in BECN1-knockdown cells after treatment with GNP-PEG/SV40 (Figure 8B). Moreover, BECN1 knockdown attenuated GNP-PEG/SV40-induced cell death $(101.6 \% \pm 4.2 \%$ to $54.1 \% \pm 1.3 \%)$ compared with control HeLa cells $(56.4 \% \pm 0.34 \%$ to $12.2 \% \pm 0.8 \%)$ at $24,48,72$, and 96 hours, suggesting that the autophagy induced by GNP-PEG/SV40 is a lethal response (Figure 8C).

\section{Effect of nucleocytoplasmic transport blockade on endoplasmic reticulum stress}

Endoplasmic reticulum stress induces both apopto$\operatorname{sis}^{40}$ and autophagy ${ }^{41}$ and occurs in response to many 

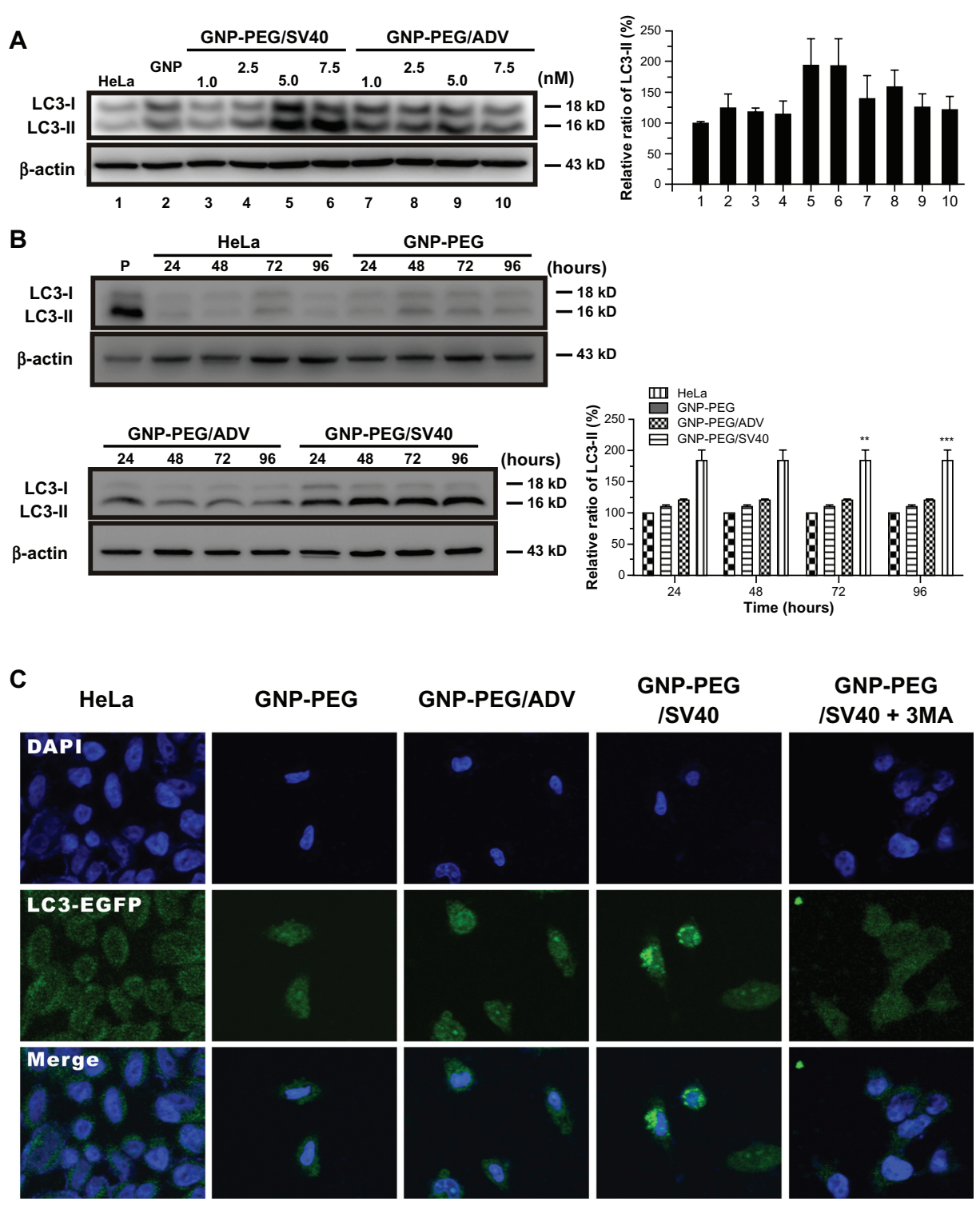

Figure 6 Autophagic cell death was induced by administration of GNP-PEG/SV40. (A) Immunoblotting for LC3-I and its cleaved form LC3-II using total cell lysates from HeLa cells treated with different concentrations (5.0 to $25 \mathrm{nM}$ ) of peptide-modified GNP ranged and (B) at a concentration of $7.5 \mathrm{nM}$ for 24 hours to 96 hours. Quantitative results for LC3-II production were normalized to $\beta$-actin protein and compared with the HeLa cells for three independent experiments. (C) EGFP-fused LC3 accumulation observed in GNP-PEG/SV40-treated HeLa cells. HeLa cells were transiently transfected with plasmid encoding EGFP-LC3, incubated for 24 hours, and then treated with peptide-modified GNP for 48 hours. Cytoplasmic LC3 vacuoles (green spots) only occurred in GNP-PEG/SV40-treated cells, and 3-methyl adenine, an inhibitor of autophagy, prevented LC3-II formation.

Notes: Data are presented as the mean \pm standard error of the mean. $* * P<0.01$; $* * * P<0.001$.

Abbreviations: ADV, adenovirus; DAPI, 4',6-diamidino-2-phenylindole; EGFP, enhanced green fluorescent protein; GNP, gold nanoparticle; PEG, poly(ethylene glycol); SV40, simian virus 40 large T antigen; LC3, microtubule-associated protein I light chain 3.

stimuli. To determine whether nucleocytoplasmic transport blockade induces the endoplasmic reticulum stress pathway, we studied the expression of endoplasmic reticulum chaperones, including immunoglobulin binding protein and CCAAT-enhancer binding protein homologous protein, after treatment with GNP-PEG/ SV40 $7.5 \mathrm{nM}$. We did not observe any increase in the expression of these two proteins in the treated cells. Therefore, nucleocytoplasmic transport blockade did not utilize endoplasmic reticulum stress-mediated autophagy (Figure S9).

\section{Discussion}

Although the internalization and trafficking of nanoparticles in cells has been well characterized, ${ }^{2,3,42}$ the long-term biological consequences of internalized nanoparticles are less clear. In this study, we demonstrated that GNP-PEG/ SV40 nanoparticles accumulate in close proximity to the 
A

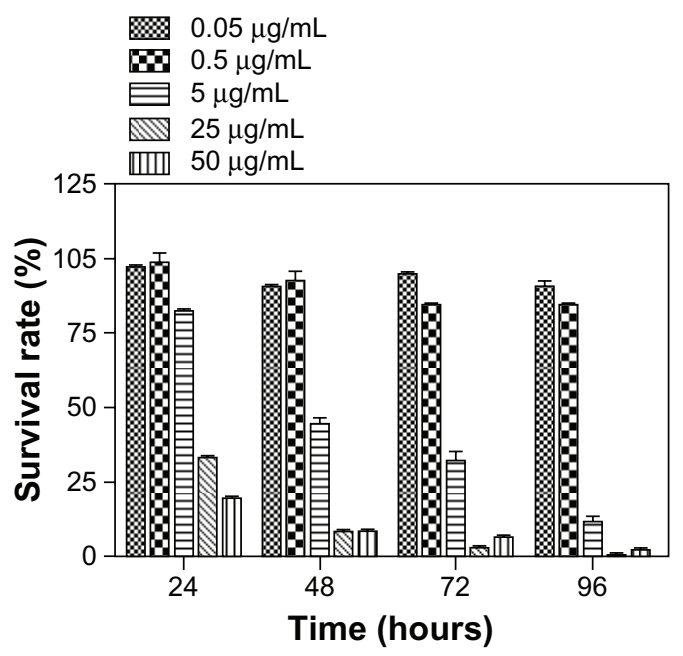

B

WGA $(\mu \mathrm{g} / \mathrm{mL})$

WGA $(5 \mu \mathrm{g} / \mathrm{mL})$
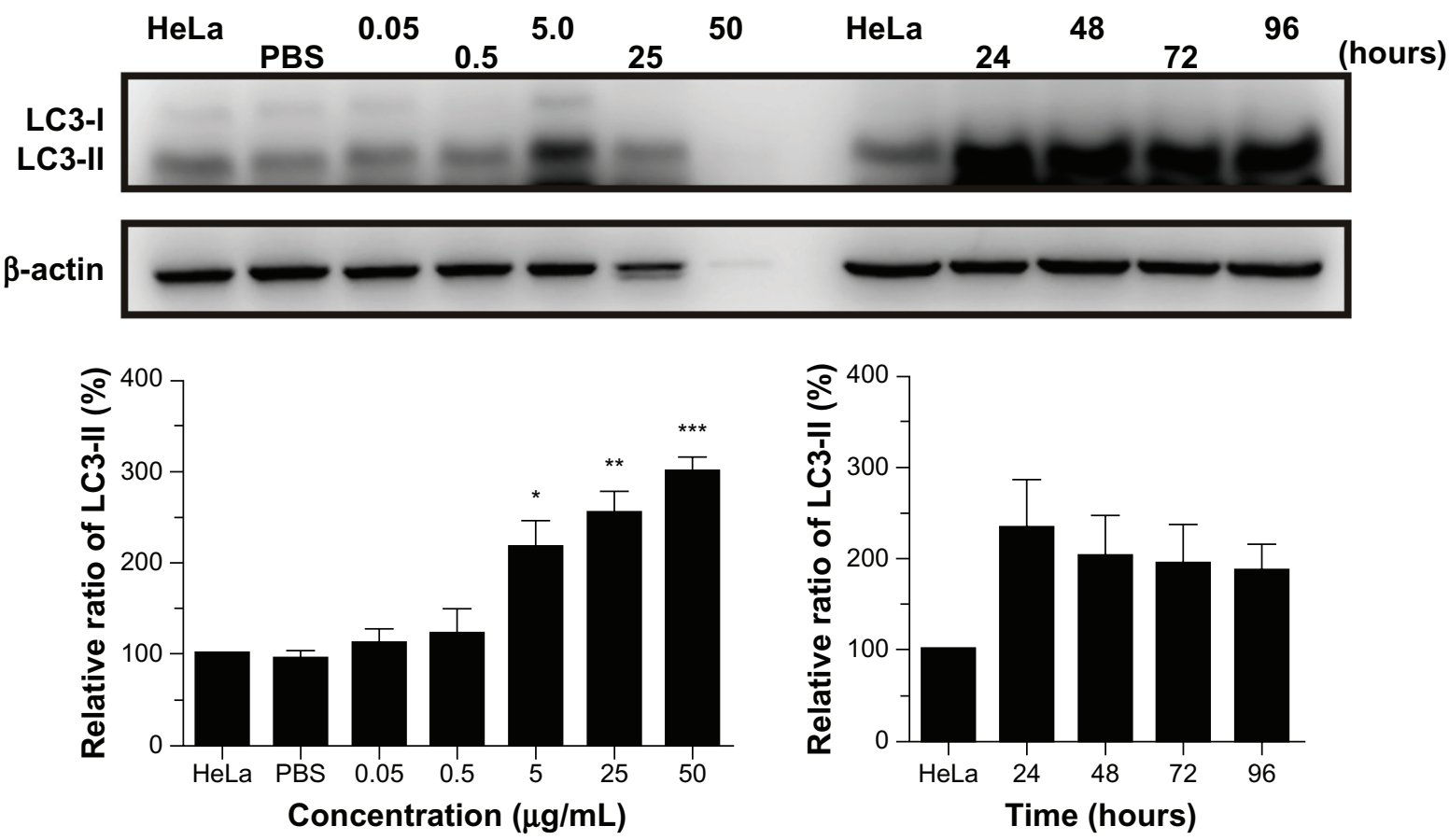

Figure 7 Autophagic cell death was induced in HeLa cells by the nuclear pore complex inhibitor wheat germ agglutinin. (A) Cytotoxicity of wheat germ agglutinin at different concentrations $(0.05,0.5,5.0,25$ and $50 \mu \mathrm{g} / \mathrm{mL})$ was measured in HeLa cells using the MTT assay. (B) Western blot for the autophagic marker LC3-II after wheat germ agglutinin treatment at different doses $(0.05,0.5,5.0,25$, and $50 \mu \mathrm{g} / \mathrm{mL})$ and for different time periods (24 to 96 hours).

Note: The results shown are the mean \pm standard error of the mean of triplicate determinations from one of three identical experiments.

Abbreviations: WGA, wheat germ agglutinin; PBS, phosphate-buffered solution; LC3, microtubule-associated protein I light chain 3.

cytoplasmic side of the nuclear membrane and induce nucleocytoplasmic transport blockade after long-term (72 hours) treatment. In turn, this blockade suppressed transportation of RNA and signaling proteins between the nucleus and the cytoplasm, subsequently inducing cell death via the autophagic pathway.

After loading GNP-PEG/SV40 into the culture medium of HeLa cells, we observed blockade of RNA export. We also found that the STAT1 and NF- $\kappa \mathrm{B}$ activated signaling proteins were no longer transported into the nucleus. These data suggest that bidirectional communication between the nucleus and the cytoplasm was blocked. The perinuclear accumulation of the particles became more prominent over time, and the nuclear pore complex structure began to change after 48 hours of treatment with GNP-PEG/ SV40 (Figure 1C). Studies using gold nanoparticles coated with nucleoplasmin, an acid nuclear protein necessary for assembly of the nucleosome, have shown that particles 
A

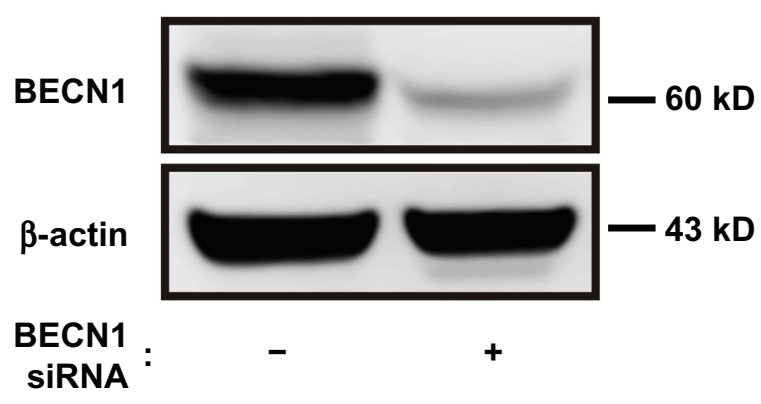

C
BECN1+

BECN1-

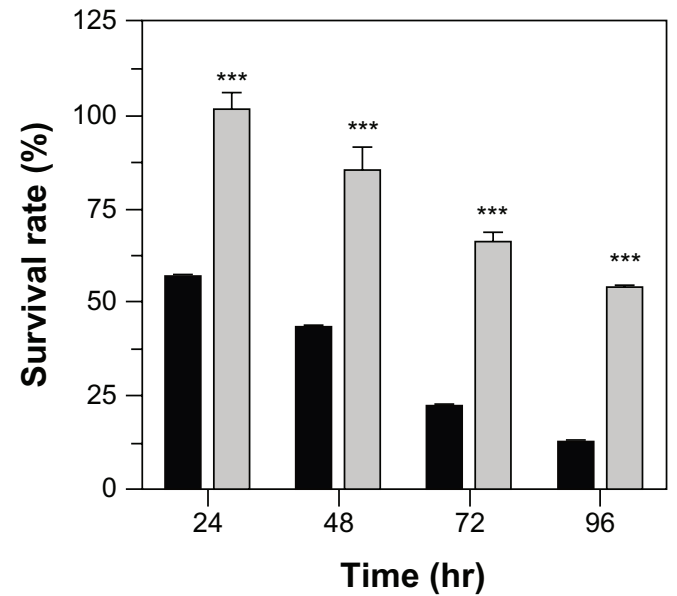

B

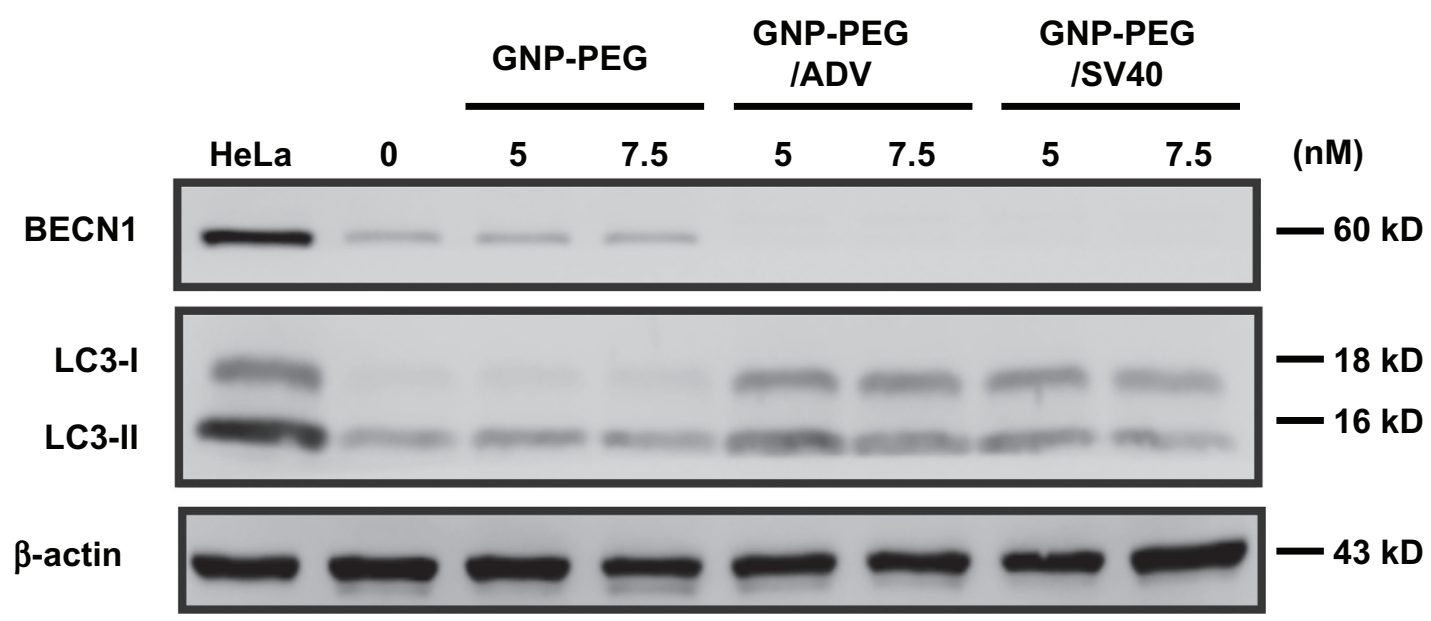

Figure 8 Knockdown of Beclin-I (BECNI) by small hairpin RNA attenuates GNP-PEG/SV40 induced autophagic cell death. (A) Expression of BECNI protein was successfully knocked down in HeLa cells. (B) Immunoblotting for LC3-II formation using total cell lysates from HeLa and BECNI-negative cells treated with each peptide-modified GNP at a concentration of 5.0 and $7.5 \mathrm{nM}$. (C) After GNP-PEG/SV40 (7.5 nM) treatment for different time periods (24 to 96 hours), cell death was significantly attenuated in BECNI-negative HeLa cells compared with control cells.

Notes: Data are shown as the mean \pm standard error of the mean. $* * * P<0.001$.

Abbreviations: ADV, adenovirus; GNP, gold nanoparticle; PEG, poly(ethylene glycol); SV40, simian virus 40 large T antigen.

localize in the central region of the transporter and obscure the ultrastructure of the nuclear pore complex. ${ }^{43}$ Therefore, blockade of the nuclear transporter disrupts the nuclear pore complex structure. Some studies ${ }^{44}{ }^{46}$ have indicated that loss of the nuclear pore complex can be caused by interference in nucleoporin expression or incorrect structural folding of nucleoporin-107 and nucleoporin-160, which affects assembly of the nuclear pore complex and formation of the conduits. Disruption of the nuclear pore complex structure by GNP-PEG/SV40 could be mediated by decreased synthesis of nucleoporins and by errors in the assembly of nuclear pore complex compounds induced by nucleocytoplasmic transport blockade. Disruption of the nuclear pore complex was confirmed by immunofluorescent staining and probing with an $\alpha$-nuclear pore complex antibody, as visualized by TEM (Figure 2).

After treatment with GNP-PEG/SV40, TEM imaging did not show pyknotic nuclei with condensed chromatin, cytoplasmic blebbing, swollen organelles, and cytoplasmic membrane rupture. Therefore, apoptotic or necrotic death in the treated cells was unlikely, according to the defined morphological criteria. In contrast, accumulation of cytoplasmic vesicles markedly increased, suggesting formation of autophagic vacuoles. Consequently, cytoplasmic vesicles resembling autophagosomes and autolysosomes developed. Therefore, the morphological findings from TEM imaging indicated autophagy as the primary mechanism of death activated by long-term treatment of HeLa cells 
with GNP-PEG/SV40. Necrotic or apoptotic cell death usually occurs within hours or one day after challenge, ${ }^{47}$ but autophagic death occurs days after stimulation. ${ }^{30,48}$ GNP-PEG/SV40 induced the death of HeLa cells, as shown by the MTT assay (Figure 5A), whereas the level of cytotoxicity began to increase 24 hours after treatment and reached its maximum 96 hours after treatment, with an $86.65 \%$ decrease in viability, supporting the assumption that autophagy was activated instead of necrotic or apoptotic death. Biochemistry studies confirmed our findings. We found no increase in cleavage of the apoptotic markers, annexin $\mathrm{V}$ and caspase 3, after long-term treatment with GNP-PEG/SV40, but we observed a significant increase in LC3-II expression and cytoplasmic aggregation of EGFPLC3 (green dots) in GNP-PEG/SV40-treated HeLa cells, suggesting activation of autophagy. Active nuclear transport is required for apoptotic signal transduction, ${ }^{49}$ and was abolished by perinuclear accumulation of GNP-PEG/SV40 in HeLa cells.

We found that blockade of nucleocytoplasmic transport mediated by GNP-PEG/SV40 depleted RNA in the cytoplasm and prevented signaling proteins from being shuttled into the nucleus. Meyer et $\mathrm{al}^{24}$ found that nucleocytoplasmic transport blockade by wheat germ agglutinin inhibits IFN- $\gamma$-induced nuclear localization of STAT1 in U3A and HeLa cells. After long-term blockade of nucleocytoplasmic transport, we observed an autophagic response in GNPPEG/SV40-treated HeLa cells. In SiHa cells, GNP-PEG/ SV40 did not accumulate in the perinuclear area. Accordingly, we did not observe autophagy in the cells. Next, we examined whether blockade of nucleocytoplasmic transport by wheat germ agglutinin induced autophagy. We detected an intense increase in LC3-II expression in HeLa and $\mathrm{SiHa}$ cells after treatment with wheat germ agglutinin. Prominent autophagy was induced in HeLa cells by GNPPEG/SV40 at a concentration of $5 \mathrm{nM}$ and in HeLa and $\mathrm{SiHa}$ cells by wheat germ agglutinin at a concentration of $5 \mu \mathrm{g} / \mathrm{mL}$.

Use of peptides to mediate the delivery and uptake of nanoparticles by specific cells has recently become a prosperous research field because it facilitates cell-specific and organelle-specific targeting and the efficient delivery of therapeutic drugs to tumor cells. Tkachenko et al ${ }^{7,8}$ reported that the cellular trajectories of nanoparticles can be achieved by a combination of target peptides and related cell types after short-term treatment (one hour). For example, SV40 peptide-modified gold nanoparticles accumulated on the cytoplasmic side of the nuclear membrane in HeLa cells but not in $3 \mathrm{~T} 3 / \mathrm{NIH}$ and HepG2 cells. Nevertheless, the purpose of such functional studies may be achieved in short experimental time courses (less than 24 hours), but they are not sufficient for observing the cellular effects, which may occur long after several rounds of the cell cycle. The role of autophagy in the pathogenesis of cancer is still controversial in terms of its tumor-suppressive and tumorigenesis roles. In general, in cells with intact apoptotic machinery, autophagy is primarily a prosurvival rather than a prodeath mechanism, ${ }^{50}$ whereas we demonstrated that autophagy induced by nuclear pore complex blockade results in cell death. Thus, we have opened up a new possibility for anticancer therapy using peptide-modified nanoparticles or wheat germ agglutinin to induce autophagic cell death in apoptotic-death resistant cancer cells. Furthermore, we found that GNP-PEG/SV40 induced autophagy in HeLa cells but not in SiHa cells, in which GNP-PEG/SV40 did not accumulate in a perinuclear manner. This autophagic behavior in HeLa cells did not occur when the modified peptide was ADV. Taken together, the data indicate that this toxic effect occurs in specific cells and is caused by specific, functionalized nanoparticles. These findings may have applications in preventing toxicities from nanoparticles in normal cells and developing new therapeutics for particular types of cancer cells, once we can use a screen to identify cancer cell-specific tropism for a certain nuclear localization signal peptide in the future.

\section{Conclusion}

We investigated the molecular mechanisms underlying the contribution of GNP-PEG/SV40 to cytotoxicity. GNP-PEG/SV40 localized around the nucleus in HeLa cells and blocked nucleocytoplasmic transport. Long-term GNP-PEG/SV40-mediated blockade of nucleocytoplasmic transport caused cell type-specific cytotoxicity. Consequently, the underlying cause of the cytotoxicity of GNP-PEG/SV40 was found to be autophagy.

\section{Acknowledgment}

The authors thank the National Science Council of Taiwan for financially supporting this research under contracts NSC 100-2120-M-006-002, NSC 101-2811-B-006-015, DOH99TD-B-111-002, DOH99-TD-C-111-003, and DOH100-TDPB-111TM014.

\section{Disclosure}

The authors report no conflicts of interest in this work. 


\section{References}

1. Chithrani BD, Ghazani AA, Chan WC. Determining the size and shape dependence of gold nanoparticle uptake into mammalian cells. Nano Lett. 2006;6(4):662-668.

2. Chithrani BD, Chan WC. Elucidating the mechanism of cellular uptake and removal of protein-coated gold nanoparticles of different sizes and shapes. Nano Lett. 2007;7(6):1542-1550.

3. Chithrani BD, Stewart J, Allen C, Jaffray DA. Intracellular uptake, transport, and processing of nanostructures in cancer cells. Nanomedicine. 2009;5(2):118-127.

4. Nativo P, Prior IA, Brust M. Uptake and intracellular fate of surfacemodified gold nanoparticles. ACS Nano. 2008;2(8):1639-1644.

5. Sahay G, Alakhova DY, Kabanov AV. Endocytosis of nanomedicines. $J$ Control Release. 2010;145(3):182-195.

6. Huang JG, Leshuk T, Gu FX. Emerging nanomaterials for targeting subcellular organelles. Nano Today. 2011;6(5):478-492.

7. Tkachenko AG, Xie H, Liu Y, et al. Cellular trajectories of peptidemodified gold particle complexes: comparison of nuclear localization signals and peptide transduction domains. Bioconjug Chem. 2004;15(3):482-490.

8. Tkachenko AG, Xie H, Coleman D, et al. Multifunctional gold nanoparticle-peptide complexes for nuclear targeting. J Am Chem Soc. 2003;125(16):4700-4701.

9. Mironava T, Hadjiargyrou M, Simon M, Jurukovski V, Rafailovichy MH Gold nanoparticles cellular toxicity and recovery: effect of size, concentration and exposure time. Nanotoxicology. 2010;4(1):120-137.

10. Conti E, Izaurralde E. Nucleocytoplasmic transport enters the atomic age. Curr Opin Cell Biol. 2001;13(3):310-319.

11. Cronshaw JM, Matunis MJ. The nuclear pore complex: disease associations and functional correlations. Trends Endocrinol Metab. 2004;15(1):34-39.

12. Pante N, Kann M. Nuclear pore complex is able to transport macromolecules with diameters of $\sim 39 \mathrm{~nm}$. Mol Biol Cell. 2002;13(2):425-434.

13. Suntharalingam M, Wente SR. Peering through the pore: nuclear pore complex structure, assembly, and function. Dev Cell. 2003;4(6): 775-789.

14. Darnell JE Jr. STATs and gene regulation. Science. 1997;277(5332): 1630-1635.

15. Meyer T, Vinkemeier U. Nucleocytoplasmic shuttling of STAT transcription factors. Eur J Biochem. 2004;271(23-24):4606-4612.

16. Yu H, Jove R. The STATs of cancer - new molecular targets come of age. Nat Rev Cancer. 2004;4(2):97-105.

17. Brasier AR. The NF-kappaB regulatory network. Cardiovasc Toxicol. 2006;6(2):111-130.

18. Gilmore TD. Introduction to NF-kappaB: players, pathways, perspectives. Oncogene. 2006;25(51):6680-6684.

19. Perkins ND. Integrating cell-signalling pathways with NF-kappaB and IKK function. Nat Rev Mol Cell Biol. 2007;8(1):49-62.

20. Takahashi N, van Kilsdonk JW, Ostendorf B, et al. Tumor marker nucleoporin $88 \mathrm{kDa}$ regulates nucleocytoplasmic transport of NFkappaB. Biochem Biophys Res Commun. 2008;374(3):424-430.

21. Carmody SR, Wente SR. mRNA nuclear export at a glance. J Cell Sci. 2009;122(12):1933-1937.

22. Hautbergue GM, Hung ML, Golovanov AP, Lian LY, Wilson SA. Mutually exclusive interactions drive handover of mRNA from export adaptors to TAP. Proc Natl Acad Sci U S A. 2008;105(13):5154-5159.

23. D'Angelo MA, Anderson DJ, Richard E, Hetzer MW. Nuclear pores form de nove from both sides of the nuclear envelope. Science. 2006; 312(5772):440-443.

24. Meyer T, Begitt A, Lodige I, Rossum MV, Vinkemeier U. Constitutive and IFN- $\gamma$-induced nuclear import of STAT1 proceed through independent pathway. EMBO J. 2002;21(3):344-354.

25. Huynh LN, Thangavel M, Chen T, Cottrell R, Mitchell JM, PraetoriusIbba M. Linking tRNA localization with activation of nutritional stress responses. Cell Cycle. 2010;9(15):3112-3118.

26. Liu WK, Sze SC, Ho JC, Liu BP, Yu MC. Wheat germ lectin induces G2/M arrest in L929 fibroblasts. J Cell Biochem. 2004;91(6): 1159-1173.
27. Mei Y, Yong J, Liu H, et al. tRNA binds to cytochrome $\mathrm{C}$ and inhibits caspase activation. Mol Cell. 2010;37(5):668-678.

28. de Bruin EC, Medema JP. Apoptosis and non-apoptotic deaths in cancer development and treatment response. Cancer Treat Rev. 2008;34(8):737-749.

29. Edinger AL, Thompson CB. Death by design: apoptosis, necrosis and autophagy. Curr Opin Cell Biol. 2004;16(6):663-669.

30. Klionsky DJ, Emr SD. Autophagy as a regulated pathway of cellular degradation. Science. 2000;290(5497):1717-1721.

31. Eskelinen EL. The dual role of autophagy in cancer. Curr Opin Pharmacol. 2011;11(4):294-300.

32. Gozuacik D, Kimchi A. Autophagy as a cell death and tumor suppressor mechanism. Oncogene. 2004;23(16):2891-2906.

33. Mathew R, Karantza-Wadsworth V, White E. Role of autophagy in cancer. Nat Rev Cancer. 2007;7(12):961-967.

34. Liu JJ, Lin M, Yu JY, Liu B, Bao JK. Targeting apoptotic and autophagic pathways for cancer therapeutics. Cancer Lett. 2011;300(2): 105-114.

35. Kabeya Y, Mizushima N, Ueno T, et al. LC3, a mammalian homologue of yeast Apg8p, is localized in autophagosome membranes after processing. EMBO J. 2000;19(21):5720-5728.

36. Levine B, Klionsky DJ. Development by self-digestion: molecular mechanisms and biological functions of autophagy. Dev Cell. 2004; $6(4): 463-477$.

37. Wu J, Dang Y, Su W, et al. Molecular cloning and characterization of rat LC3A and LC3B - two novel markers of autophagosome. Biochem Biophys Res Commun. 2006;339(1):437-442.

38. Mizushima N. Methods for monitoring autophagy. Int J Biochem Cell Biol. 2004;36(12):2491-2502.

39. Liu Y, Shipton MK, Ryan J, Kaufman ED, Franzen S, Feldheim DL. Synthesis, stability, and cellular internalization of gold nanoparticles containing mixed peptide-poly(ethylene glycol) monolayers. Anal Chem. 2007;79(6):2221-2229.

40. Wali VB, Bachawal SV, Sylvester PW. Endoplasmic reticulum stress mediates gamma-tocotrienol-induced apoptosis in mammary tumor cells. Apoptosis. 2009;14(11):1366-1377.

41. Zhou L, Zhang J, Fang Q, et al. Autophagy-mediated insulin receptor down-regulation contributes to endoplasmic reticulum stress-induced insulin resistance. Mol Pharmacol. 2009;76(3):596-603.

42. Mahmood M, Casciano DA, Mocan T, et al. Cytotoxicity and biological effects of functional nanomaterials delivered to various cell lines. J Appl Toxicol. 2010;30(1):74-83.

43. Rutherford SA, Goldberg MW, Allen TD. Three-dimensional visualization of the route of protein import: the role of nuclear pore complex substructures. Exp Cell Res. 1997;232(1):146-160.

44. Boehmer T, Enninga J, Dales S, Blobel G, Zhong H. Depletion of a single nucleoporin, Nup107, prevents the assembly of a subset of nucleoporins into the nuclear pore complex. Proc Natl Acad Sci USA. 2003;100(3):981-985.

45. Harel A, Orjalo AV, Vincent T, et al. Removal of a single pore subcomplex results in vertebrate nuclei devoid of nuclear pores. Mol Cell. 2003;11(4):853-864.

46. Walther TC, Alves A, Pickersgill H, et al. The conserved Nup107-160 complex is critical for nuclear pore complex assembly. Cell. 2003; 113(2):195-206.

47. Bursch W, Paffe S, Putz B, Barthel G, Schulte-Hermann R. Determination of the length of the histological stages of apoptosis in normal liver and in altered hepatic foci of rats. Carcinogenesis. 1990;11(5):847-853.

48. Amaravadi RK, Thompson CB. The roles of therapy-induced autophagy and necrosis in cancer treatment. Clin Cancer Res. 2007; 13(24):7271-7279.

49. Yasuhara H, Equchi Y, Tachibana T, Imamoto N, Yoneda Y, Tsujimoto Y. Essential role of active nuclear transport in apoptosis. Genes Cells. 1997;2(1):55-64.

50. Maiuri MC, Zalckvar E, Kimchi A, Kroemer G. Self-eating and selfkilling: crosstalk between autophagy and apoptosis. Nat Rev Mol Cell Biol. 2007;8(9):741-752. 


\section{Supplementary figures}
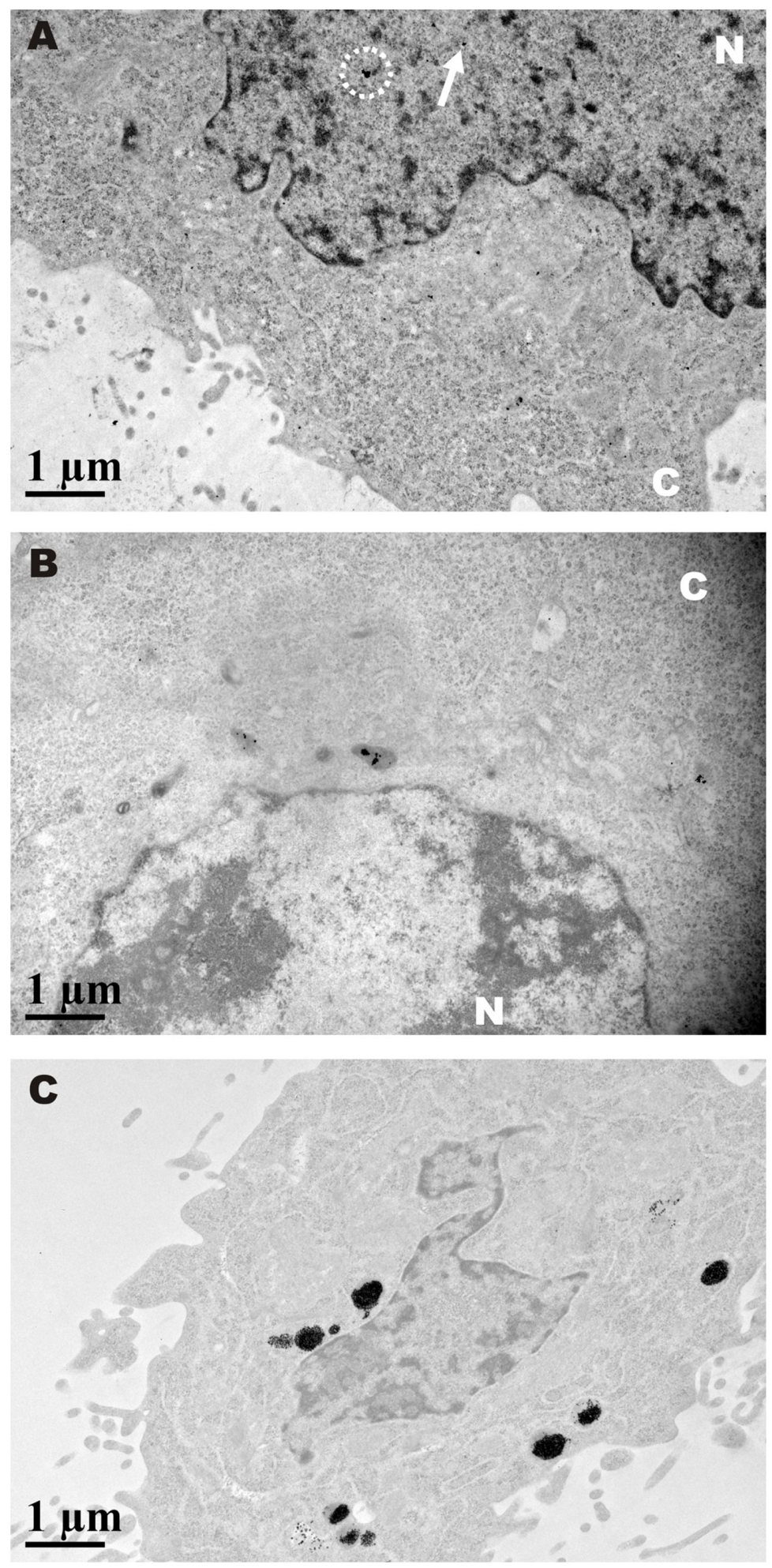

Figure SI Cellular uptake of GNP-PEG/ADV for different time points. (A) After 6 hours of incubation, only a small amount of GNP-PEG/ADV was capable of targeting the nuclear compartment in aggregated (white circle) or dispersed form (arrow). (B) It was then exported from the nucleus after 12 hours of treatment. (C) After 48 hours, a large proportion of GNP-PEG/ADV was grouped inside the small vesicles (protein body). No nuclear membrane accumulation or nucleocytoplasmic transport blockade was found in the control group.

Abbreviations: ADV, adenovirus; GNP, gold nanoparticle; PEG, poly(ethylene glycol); N, nucleus; C, cytoplasm. 


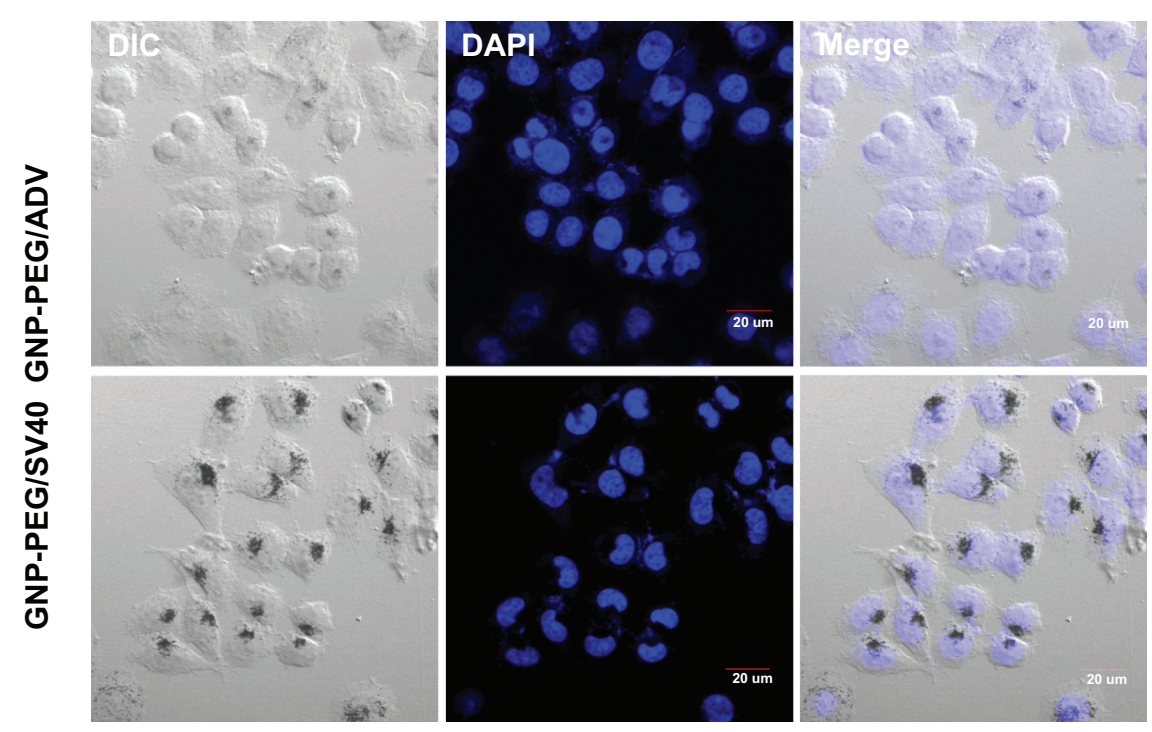

Figure S2 Cellular localization of different peptide-modified gold nanoparticles was analyzed by laser confocal microscopy in SiHa cells. GNP-PEG/SV40 accumulated focally in the perinuclear area of the cytoplasm, but only translocalized into the nucleus in the GNP-PEG/ADV-treated group.

Abbreviations: ADV, adenovirus; GNP, gold nanoparticle; PEG, poly(ethylene glycol); SV40, simian virus 40 large T antigen.

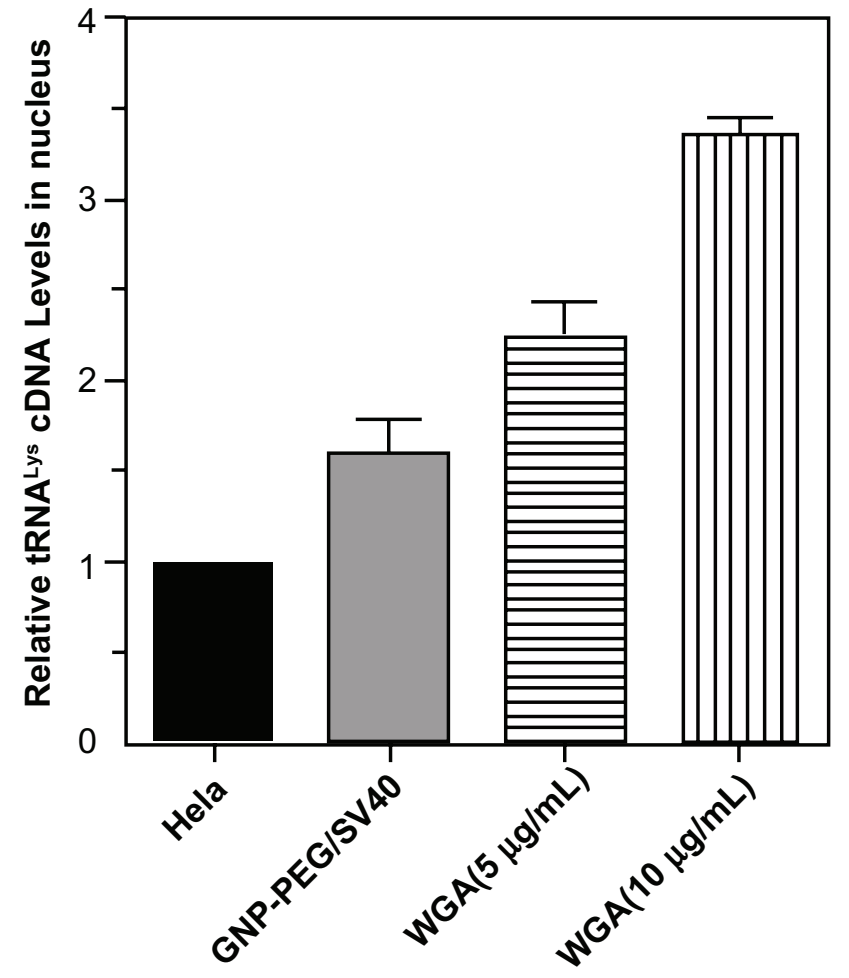

Figure S3 Cellular localization of tRNA ${ }^{\text {Lys }}$ in HeLa cells treated with GNP-PEG/SV40 and wheat germ agglutinin (WGA). Quantitative reverse transcriptase polymerase chain reaction were performed with nuclear RNA isolated from GNP-PEG/SV40 (7.5 nM) and WGA treated HeLa cells. Increased nuclear accumulation of tRNA ${ }^{\text {Lys }}$ confirmed nucleocytoplasmic transport blockade in HeLa cells treated with GNPPEG/SV40 and WGA.

Abbreviations: GNP, gold nanoparticle; PEG, poly(ethylene glycol); SV40, simian virus 40 large $\mathrm{T}$ antigen.

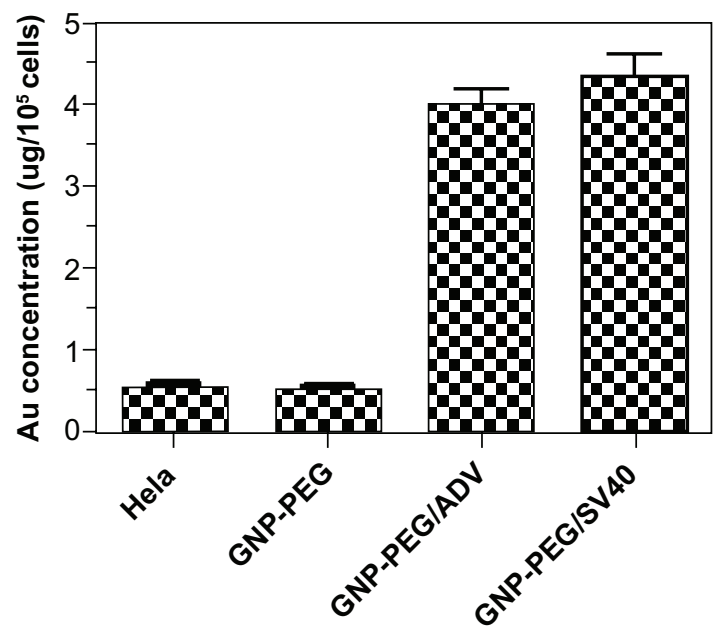

Figure S4 Quantification of peptide-modified gold nanoparticle internalization via atomic absorption spectrometry. Analysis of GNP-PEG, GNP-PEG/ADV, and GNP-PEG/SV40 uptake by HeLa cells exposed to $7.5 \mathrm{nM}$ nanoparticles for 24 hours. No significant difference in uptake was found between GNP-PEG/ADV-treated and

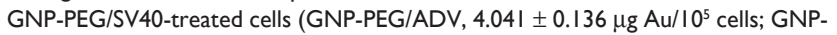
PEG/SV40, $4.358 \pm 0.253 \mu \mathrm{g} \mathrm{Au/} / 0^{5}$ cells).

Abbreviations: ADV, adenovirus; GNP, gold nanoparticle; PEG, poly(ethylene glycol); SV40, simian virus 40 large T antigen. 


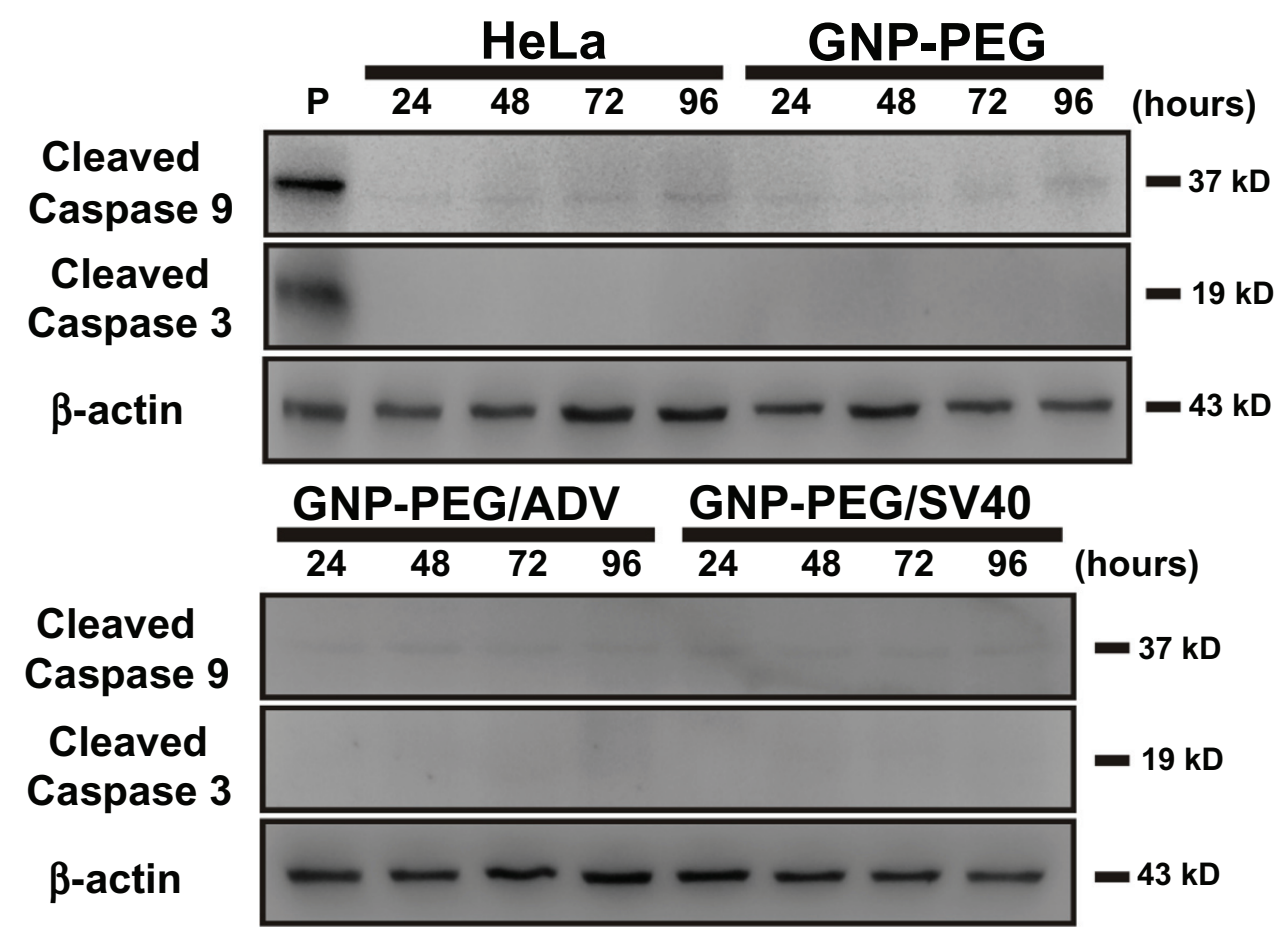

Figure S5 GNP-PEG/SV40-induced cell death did not involve the caspase-dependent mechanism of apoptosis. Cells treated with peptide-modified gold nanoparticles (72 $\mu \mathrm{g} /$ $\mathrm{mL}$ ) were harvested at different times $(24,48,72$, and 96 hours after treatment) and were immunoblotted for caspase- 9 and activated caspase-3. $\beta$-Actin was used as the loading control. P refers to positive controls (cisplatin-treated HeLa cells). No detectable activated caspase protein was found within the treated cells, indicating the death mechanism was not via the apoptosis signaling pathway.

Abbreviations: ADV, adenovirus; GNP, gold nanoparticle; PEG, poly(ethylene glycol); SV40, simian virus 40 large T antigen. 
A

B
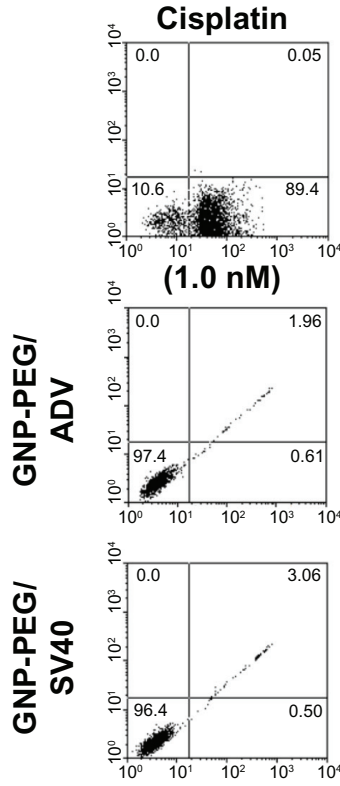

HeLa

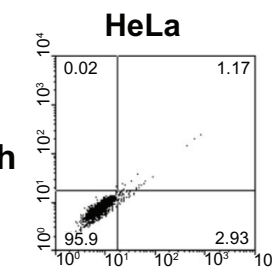

$48 \mathrm{~h}$

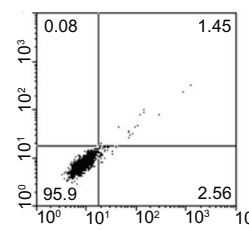

$72 \mathrm{~h}$
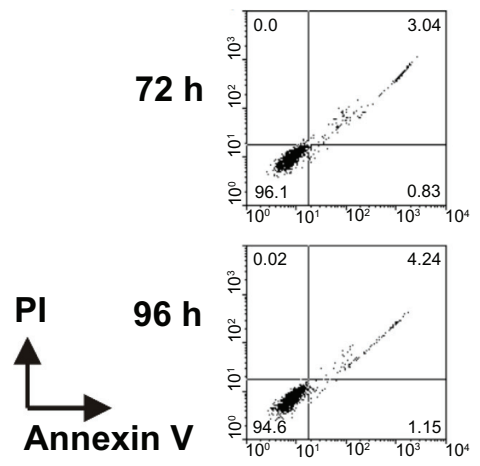
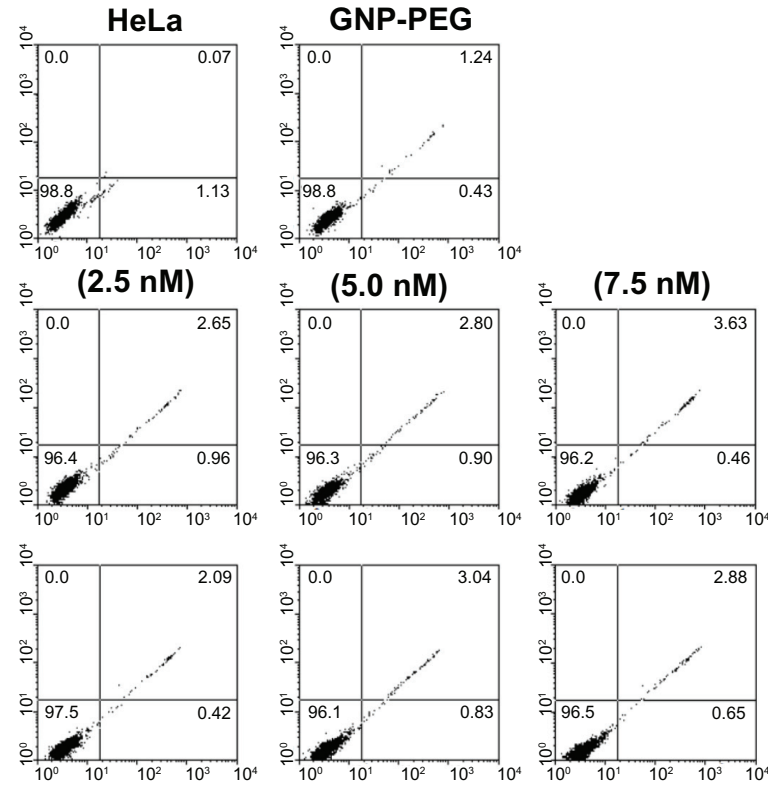

GNP-PEG/
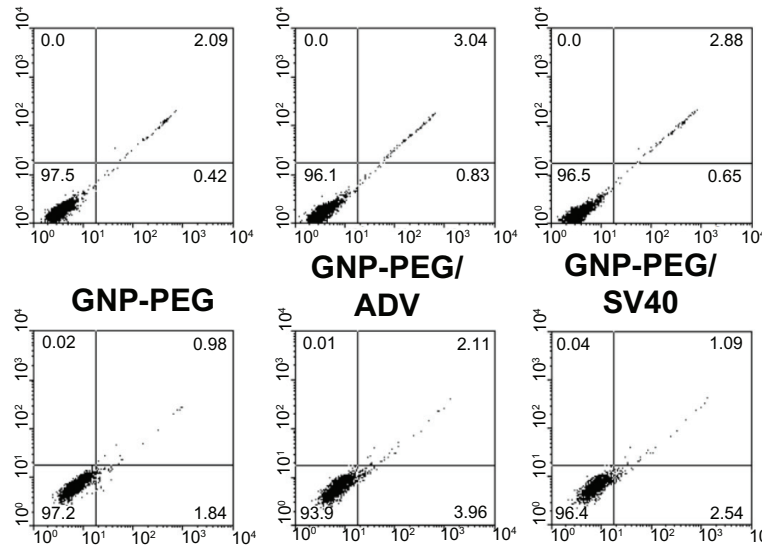

GNP-PEG/

SV40
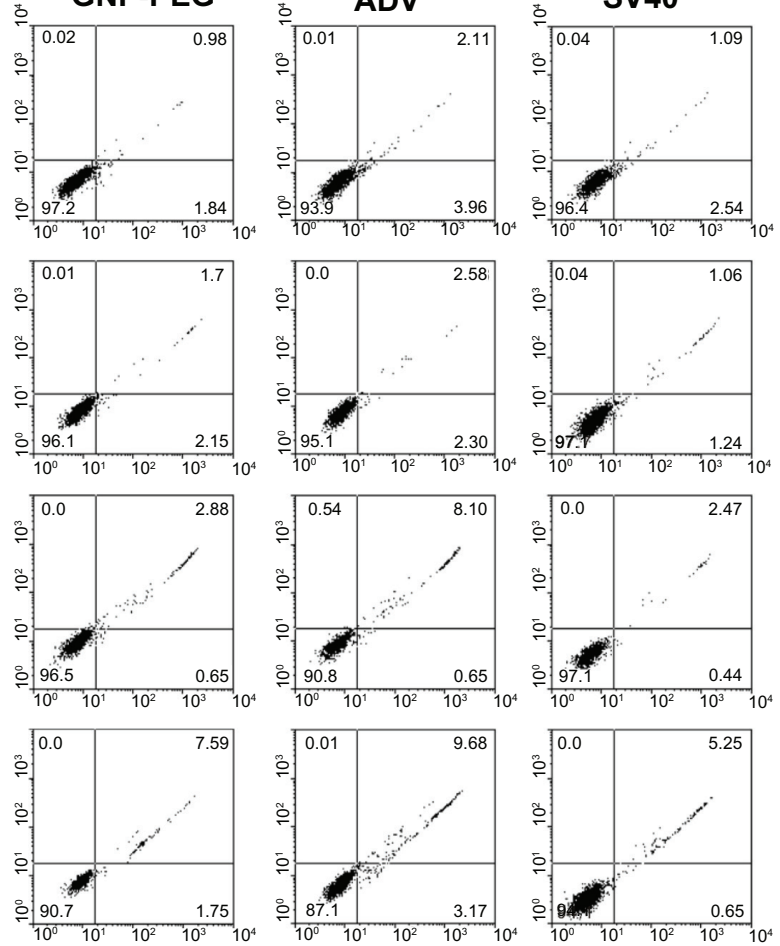

Figure S6 GNP-PEG/SV40-induced cell death did not involve the mechanism of necrosis and early apoptosis. Flow cytometric profiling of annexin-V/propidium iodide double staining shows necrotic cells in the top right quadrant, apoptotic cells in the lower right quadrant, and viable cells in the bottom left quadrant. During treatment with GNPPEG/SV40, the annexin-V/propidium iodide staining was similar to that of the HeLa cell control located in the bottom left quadrant at (A) various concentrations ( $9.6,24,48$ and $72 \mu \mathrm{g} / \mathrm{mL}$ ) and (B) time periods ( 24 hours to 96 hours) of treatment. P refers to positive controls (cisplatin-treated HeLa cells at $50 \mu M$ for 24 hours). Abbreviations: ADV, adenovirus; GNP, gold nanoparticle; PEG, poly(ethylene glycol); PI, propidium iodide; SV40, simian virus 40 large T antigen. 


\section{A}

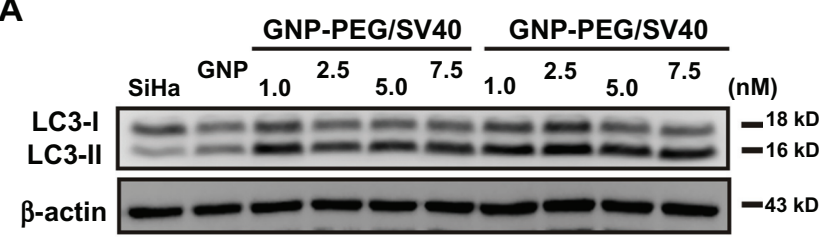

B

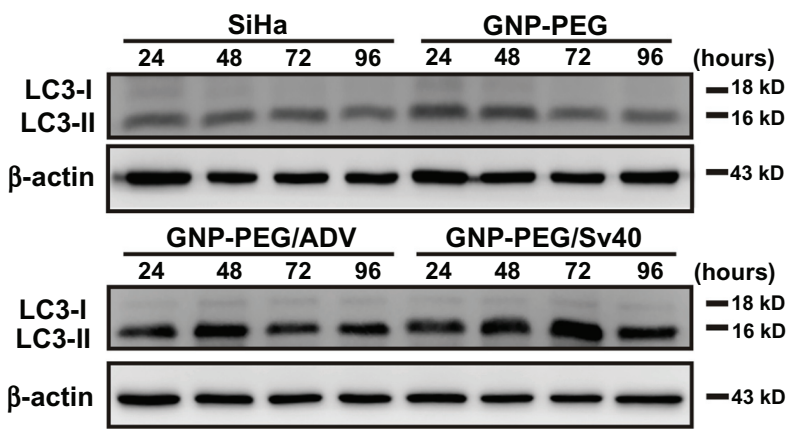

Figure S7 Autophagic cell death was not induced by GNP-PEG/SV40 in SiHa cells. Immunoblotting for LC3-I and its cleaved form LC3-II using total cell lysates (5 $\mu \mathrm{g}$ ) from $\mathrm{SiHa}$ cells at $(\mathbf{A})$ different concentrations of peptide-modified GNP ranging from 9.6 to $72 \mu \mathrm{g} / \mathrm{mL}$ and (B) at the concentration of $72 \mu \mathrm{g} / \mathrm{mL}$ for 24 hours to 96 hours.

Abbreviations: ADV, adenovirus; GNP, gold nanoparticle; PEG, poly(ethylene glycol); SV40, simian virus 40 large T antigen; LC3, microtubule-associated protein I light chain 3.

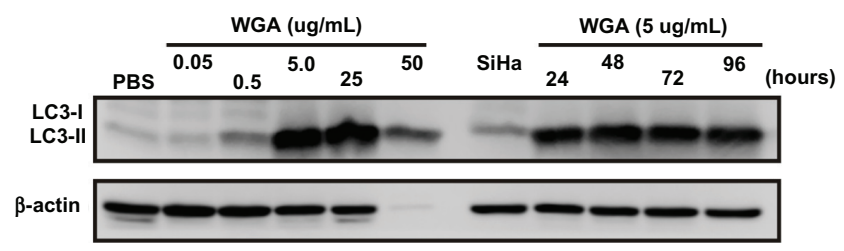

Figure S8 Autophagic cell death was induced by the nuclear pore complex inhibitor, wheat germ agglutinin (WGA), in SiHa cells. The autophagic marker, LC3II, was probed by Western blotting of WGA given at different doses $(0.05,0.5,5.0$, 25 , and $50 \mu \mathrm{g} / \mathrm{mL}$ ) and time periods (24 to 96 hours). After treatment, autophagy increased significantly at $5.0,25$, and $50 \mu \mathrm{g} / \mathrm{mL}$ concentrations and was expressed from 24 hours to 96 hours.

Abbreviations: LC3, microtubule-associated protein I light chain 3; PBS, phosphate-buffered saline.

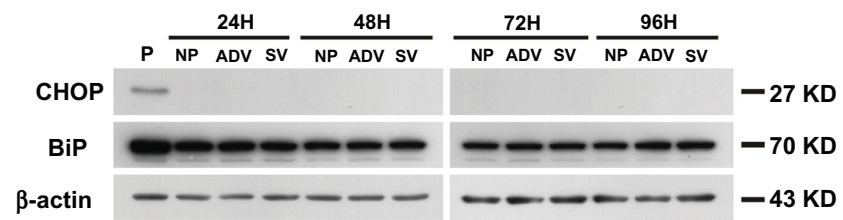

Figure S9 The cell death mechanism of GNP-PEG/SV40-mediated nucleocytoplasmic transport blockade was not via the endoplasmic reticulum stress pathway. The effects of each group throughout different time periods on the relative intracellular levels of $\mathrm{CHOP}$ and $\mathrm{BiP}$ were assessed by Western blot analysis. Whole cell lysates were collected for the assay. $\beta$-Actin was visualized to ensure equal loading in each lane. The expressed level of $\mathrm{CHOP}$ was undetectable in each group and without any change of BiP under treatment.

Abbreviations: $A D V$, adenovirus; $B i P$, immunoglobulin heavy chain binding protein in pre-B cell; CHOP, CCAAT-enhancer binding protein homologous protein; GNP, gold nanoparticle; PEG, poly(ethylene glycol); SV40, simian virus 40 large T antigen; P, positive control.
International Journal of Nanomedicine

\section{Publish your work in this journal}

The International Journal of Nanomedicine is an international, peerreviewed journal focusing on the application of nanotechnology in diagnostics, therapeutics, and drug delivery systems throughout the biomedical field. This journal is indexed on PubMed Central, MedLine, CAS, SciSearch ${ }^{\circledR}$, Current Contents ${ }^{\circledR} /$ Clinical Medicine,

\section{Dovepress}

Journal Citation Reports/Science Edition, EMBase, Scopus and the Elsevier Bibliographic databases. The manuscript management system is completely online and includes a very quick and fair peer-review system, which is all easy to use. Visit http://www.dovepress.com/ testimonials.php to read real quotes from published authors. 